\title{
COVID-19 Is a Multi-Organ Aggressor: Epigenetic and Clinical Marks
}

OPEN ACCESS

Edited by:

Ping An,

Frederick National Laboratory for Cancer Research (NIH), United States

Reviewed by:

Sayuri Seki,

National Institute of Infectious Diseases (NIID), Japan

Sunil Joshi,

University of Miami, United States

*Correspondence: Mankgopo Magdeline Kgatle mankgopo.kgatle@sanumeri.co.za; kgatle.mankgopo@gmail.com Mike Machaba Sathekge mike.sathekge@up.ac.za

Specialty section: This article was submitted to Microbial Immunology, a section of the journal Frontiers in Immunology

Received: 02 August 2021 Accepted: 21 September 2021 Published: 08 October 2021

Citation: Kgatle MM, Lawal IO, Mashabela G, Boshomane TMG, Koatale PC, Mahasha PW, Nollovu H, Vorster M, Rodrigues $H G$, Zeevaart JR, Gordon S, Moura-Alves $P$ and

Sathekge MM (2021) COVID-19 Is a Multi-Organ Aggressor: Epigenetic and Clinical Marks.

Front. Immunol. 12:752380. doi: 10.3389/fimmu.2021.752380

\author{
Mankgopo Magdeline Kgatle ${ }^{1,2^{*}}$, Ismaheel Opeyemi Lawal ${ }^{1,2,3}$, Gabriel Mashabela ${ }^{4}$, \\ Tebatso Moshoeu Gillian Boshomane ${ }^{1,2,3,5}$, Palesa Caroline Koatale ${ }^{1,2}$, \\ Phetole Walter Mahasha ${ }^{6}$, Honest Ndlovu ${ }^{2}$, Mariza Vorster ${ }^{2}$, Hosana Gomes Rodrigues ${ }^{7}$, \\ Jan Rijn Zeevaart ${ }^{1,8,9}$, Siamon Gordon ${ }^{9,10}$, Pedro Moura-Alves ${ }^{11}$ \\ and Mike Machaba Sathekge ${ }^{1,2,4 *}$
}

\begin{abstract}
${ }^{1}$ Nuclear Medicine Research Infrastructure (NuMeRI), Steve Biko Academic Hospital, Pretoria, South Africa, ${ }^{2}$ Department of Nuclear Medicine, University of Pretoria \& Steve Biko Academic Hospital, Pretoria, South Africa, ${ }^{3}$ Department of Nuclear Medicine, Steve Biko Academic Hospital, Pretoria, South Africa, ${ }^{4}$ SAMRC/NHLS/UCT Molecular Mycobacteriology Research Unit, DSI/NRF Centre of Excellence for Biomedical TB Research, Department of Pathology and Institute of Infectious Disease and Molecular Medicine, Faculty of Health Sciences, University of Cape Town, Cape Town, South Africa, ${ }^{5}$ Nuclear and Oncology Division, AXIM Medical (Pty), Midrand, ${ }^{6}$ Precision Medicine and SAMRC Genomic Centre, Grants, Innovation, and Product Development (GIPD) Unit, South African Medical Research Council, Pretoria, South Africa, ${ }^{7}$ Laboratory of Nutrients and Tissue Repair, School of Applied Sciences, University of Campinas, Campinas, Brazil, ${ }^{8}$ South African Nuclear Energy Corporation, Radiochemistry and NuMeRI PreClinical Imaging Facility, Mahikeng, South Africa, ${ }^{9}$ Graduate Institute of Biomedical Sciences, College of Medicine, Chang Gung University, Taoyuan City, Taiwan, ${ }^{10}$ Sir William Dunn School of Pathology, University of Oxford, Oxford, United Kingdom, ${ }^{11}$ Ludwig Institute for Cancer Research, Nuffield Department of Medicine, University of Oxford, Oxford, United Kingdom
\end{abstract}

The progression of coronavirus disease 2019 (COVID-19), resulting from a severe acute respiratory syndrome coronavirus 2 (SARS-CoV-2) infection, may be influenced by both genetic and environmental factors. Several viruses hijack the host genome machinery for their own advantage and survival, and similar phenomena might occur upon SARS-CoV-2 infection. Severe cases of COVID-19 may be driven by metabolic and epigenetic driven mechanisms, including DNA methylation and histone/chromatin alterations. These epigenetic phenomena may respond to enhanced viral replication and mediate persistent long-term infection and clinical phenotypes associated with severe COVID-19 cases and fatalities. Understanding the epigenetic events involved, and their clinical significance, may provide novel insights valuable for the therapeutic control and management of the COVID19 pandemic. This review highlights different epigenetic marks potentially associated with COVID-19 development, clinical manifestation, and progression.

Keywords: ACE2, COVID-19, cytokine storm, epigenetics, multi-organ, pro-inflammatory cytokines, SARS-CoV-2, TMPRSS2

\section{MAIN BACKGROUND}

Epigenetics is a branch of biology arising from inheritable gene transcription alterations in response to environmental cues, such as pollutants, chemicals, radiation, diet, stress, and pathogenic organisms (1). Epigenetic phenomena do not cause any genetic alterations or mutations. However, as the new phenotypes that are somatically heritable, epigenetic tags alter gene 
transcription and normal functions. Epigenetic marks are either suppressive or active and include DNA methylation, histone modification/chromatin remodelling, non-coding RNA, and RNA modification (Figure 1). These marks are implicated in activating or suppressing gene promoters, bodies, or transposable elements in normal processes such as ageing, genomic imprinting, and X-chromosome inactivation (2). DNA methylation is the best-studied stable epigenetic mark that occurs within $\mathrm{CpG}$ island promoter regions enriched with $>70 \%$ of $\mathrm{CpG}$ (cytosine phosphate guanine) sites in the genome (3). It involves tagging or deposition of the methyl group of 5methylcytosine to the DNA molecule through catalysis by DNA methyltransferases (DNMTs), which can be reversed by another family of enzymes called ten-eleven translocation (Tet 1-3) methyldioxygenases (4). DNMTs are regarded as writers of DNA methylation, recognised or read by methyl-CpG binding domains (MBDs) and then erased by TETs (Figure 1).

Eukaryotic cell DNA is packaged into chromatin wrapped around an octamer of four core histone proteins (5). Histones can be post-translationally modified by repressive or active histone marks that impact the interaction of histones with DNA or the occupancy of transcriptional machineries for gene expression (Figure 1). They dictate the chromatin transcriptional state of the local genomic regions via histone

A

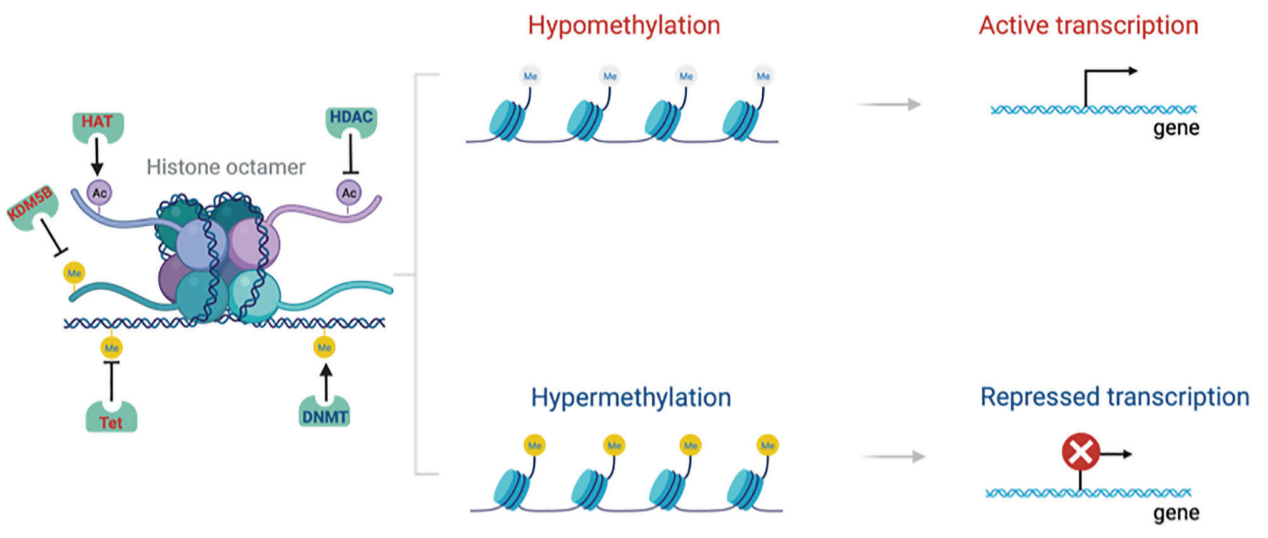

Enzyme Methylated $\cdots$ Unmethylated Ac Acetylated

B

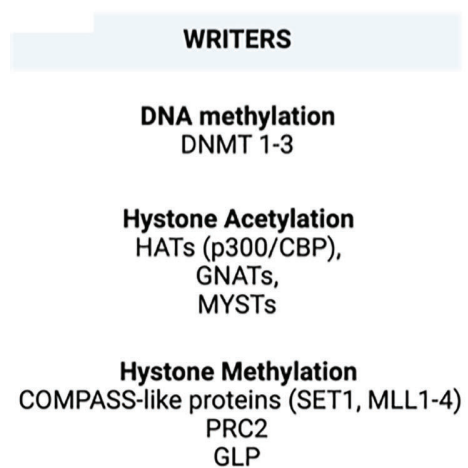

READERS

DNA methylation

MBDs

Hystone Acetylation

Bromodomains
Hystone Methylation
Cromodomains
PHD fingers
Ankyrin repeats

ERASERS

DNA methylation

TET 1-3
Hystone Acetylation
HDAC 1-11
Sirtuins (SIRT 1-7)

Hystone Methylation
KDM 1-6
LSD 1-2
UTX1
JMJD 1-3

FIGURE 1 | Chromatin structure. (A) A 147bp DNA wraps around the histone octamer with two copies of each of the histones H2A, H2B, H3, and H4. Various epigenetic mechanisms that modify chromatin, such as DNA methylation and histone modifications, are highlighted. DNA and histone methylation collaborate with different modifying enzymes and creates a tightly packed chromatin and suppress gene transcription by preventing the transcription machinery from binding DNA. Histone acetylation perturbs structural electrostatic interactions between the DNA and histones, resulting in the less compact structure of chromatin structure. This allows DNA access by transcription factors that promote gene transcription. (B) Writing, erasing, and reading chromatin methylation markers are highlighted. These mark various sites on the tail and globular domains of histones. Writers and erasers are methyltransferases and demethylases, respectively. These are recognised by distinct effector proteins called readers. (Created with BioRender.com) ac, Acetylation; DNMT, DNA methyltransferase; GLP, G9a-like protein; GNATs, Gcn5-related N-acetyltransferases; HATs, Histone acetyltransferases; HDACs, Histone deacetylases; JmjC, Jumonji C; KDM, Histone lysine demethylases; LSD, Lysine-specific demethylases; MBDs, Methyl-CpG binding domains; me, Methylation; MLL, Mixed-lineage leukaemia; PHD - Plant homeodomain; PRC2, Polycomb repressive complex 2; p300/CBP, p300 and cyclic AMP response element-binding protein; SET1, Suppressor of variegation 3-9, Enhancer of Zeste, Trithorax 1; SIRT, sirtuins; TET, Ten-eleven translocation; UTX1, Ubiquitously transcribed tetratricopeptide repeat, X chromosome 1. 
methylation, acetylation, ubiquitination, and phosphorylation. Chromatin forms a higher-order structure classified as euchromatin and heterochromatin (6). Euchromatin is a loosely packed or open form of chromatin enriched with DNA accessible to regulatory transcription complexes and promotes active gene transcription. Excessive acetylation of histone lysine residues is a common feature of euchromatin (7). It correlates with COMPASS-like proteins as binding partners and methylation of lysine 4 of histone 3 (H3K4), H3K36, and H3K79 that mark transcriptional activation of enhancers, gene promoters, and transcribed genes in gene bodies, respectively (810). Lysine can be mono-(me1), di- (me2), or tri-methylation (me3), providing unique functionality to each methylation site (9, 11). A tight or closed form of chromatin is called heterochromatin, protecting the DNA from being accessible to repressive transcriptional marks that restrict gene expression. Heterochromatin is further categorized into constitutive and facultative heterochromatins that are enriched in hypoacetylated or hypomethylated histones (9). The former is a stable form of heterochromatin comprised of repetitive DNA sequences (called DNA satellites) located at the transposon elements, centromere, and telomere. It is characterised by a repressive $\mathrm{H} 3 \mathrm{~K} 9$ epigenetic mark and heterochromatin protein 1 (HP1) chromodomain binding partner $(8,9,12-14)$. Facultative heterochromatin is enriched with long interspersed nucleotide elements (LINE)-type sequences, repressive $\mathrm{H} 3 \mathrm{~K} 27 \mathrm{me} 2 / 3$ epigenetic mark and its binding partner, polycomb repressive complex 2 (PRC2)enhancer of zeste homolog 2 (EHZ2) $(15,16)$.

Writers, readers, and erasures of DNA methylation and histone modifications are listed in Figure 1. This review will discuss the role of epigenetics in COVID-19 infection, susceptibility to infection, and clinical markers established systemically during COVID-19 and may be associated with various epigenetic alterations.

\section{MECHANISMS OF SARS-COV-2 VIRAL INFECTION AND MULTI-ORGAN SYSTEM INVASION}

\section{ACE2 and TMPRSS2: Viral Entry and Regulation}

Severe acute respiratory syndrome coronavirus 2 (SARS-CoV-2) is the aetiological agent of the current pandemic, coronavirus disease 2019 (COVID-19) (17). This pathogen is enabled by the angiotensin-converting enzyme 2 (ACE2) (18). Mechanistically, SARS-CoV-2 penetrates and enters the host cell by binding to the ACE2 receptor as the primary target. This is facilitated by proteolytic priming by the cellular transmembrane serine protease 2 (TMPRSS2) (19). In the proposed model of respiratory failure, SARS-CoV-2 downregulates ACE2 through the SARS-CoV spike (SARS-S) protein, explaining the reninangiotensin-aldosterone systems (RAAS) dysregulation and cardiotoxicity in severe COVID-19 infection (20). Suppression of ACE2 also induces tumour necrosis factor alpha (TNF- $\alpha$ ) converting enzyme (TACE) that antagonises ACE2 shedding of the SARS-S (19). Modulation of TACE activity by SARS-S protein was found to depend on the cytoplasmic domain of ACE2 as ACE2 mutants devoid of the carboxyl-terminal region could not induce ACE2 shedding or TNF- $\alpha$ production (21). Moreover, deletion of the cytoplasmic tail of ACE2 or knockdown of TACE expression significantly attenuates viral infection (21). It has been shown that Ang II induces ACE2 shedding by promoting TACE activity as a positive feedback mechanism, suggesting that SARS-CoV mediated ACE2 down-regulation will promote Ang II accumulation and HIF- $1 \alpha$ activation, which positively activates disintegrin and metalloproteinase domaincontaining protein 17 (ADAM17) activity, thus perpetuating membrane shedding of ACE2, RAAS overactivation, and inflammation (22-26). This mechanism, however, is not universal to all coronaviruses because the spike protein of HNL63-CoV (NL63-S), a coronavirus that also utilizes ACE2 and is known to cause common influenza, did not produce similar cellular responses (21).

\section{Lung as the Primary Target for SARS-CoV-2 Infection}

SARS-CoV-2 infection is primarily a respiratory infection that targets type II alveolar epithelial cells $(83 \%)$ in the lungs $(27,28)$. Upregulation of ACE2 in various cells usually disrupts ACE2 normal function from cleaving and converting angiotensin II to angiotensin 1-7 for tissue protection (29). SARS-CoV-2-infected type II alveolar epithelial cells leads to inflammation and severe damage in the lung tissue that is clinically manifested by elevated levels of ferritin and D-dimer, and association with oxygen desaturation, chest pain, and disease progression as indicated by computed tomography (CT) pulmonary angiography $(30,31)$. Elevated levels of macrophage/monocyte colony-stimulating factor (M-CSF, also known as colony-stimulating factor 1 receptor), granulocyte-monocyte colony-stimulating factor (GM-CSF), and interleukin (IL)-6 have also been reported in the later stages of COVID-19 (32-34). This correlates with pneumonia and acute respiratory distress syndrome (ARDS) that may lead to organ failure as observed in severe or critical cases of COVID-19 (31, 33, 35-37).

Most recently, the study of Ferreira-Gomes et al. (38) has shown that cells isolated from bronchoalveolar lavage of intensive care unit (ICU) patients with severe COVID-19 cases were enriched with tumour growth factor-beta 1 (TGF- $\beta 1$ )expressing Th17, regulatory $\mathrm{T}$ cells, and CD14-positive cells, immune cells that are usually recruited to fight the infection. TGF- $\beta 1$ is a master regulator of immune reaction and pulmonary fibrosis in COVID-19 patients (39). Its expression was associated with SARS-CoV-2 spike protein-specific IgM, IgG (IgG1 and IgG2), and IgA (IgA1 and IgA2) antibodies that protect systemic organs and mucosal surfaces, respectively (38, 40). SARS-CoV-2 spike protein-specific antibodies were also an indication of ongoing immune reaction and damage in secondary organs from the spread of viral infection (41). In the early days of ICU admission, IgG antibodies are predominantly generated by IL-10/21 specific to SARS-CoV-2 proteins (42). As a result of clonal expansion, later these antibodies become somatically mutated, virus non-specific, and undergo switching as instructed by TGF- $\beta 1(38,43)$. Ferreira-Gomes and co- 
authors have demonstrated that TGF- $\beta 1$ induces chronic immune reaction by regulating antibody switching from IgG to $\operatorname{IgA}$ and this correlates with prolonged ICU stays of more than seven days (38).

Overall, systemic COVID-19 infection is characterised by various immunoregulatory and pro-inflammatory cytokines such as IL-1 $\beta$, IL-2, IL-6, IL-7, IL-10, IL-18, D-Dimer, C-reactive protein (CRP), GM-CSF, interferon gamma-induced protein 10 (IP10), macrophage inflammatory protein 1 alpha (MIP1 $\alpha$ ), chemokine (C-C motif) ligand 2 (CCL2, also known as MCP1), interferon gamma (IFN- $\gamma$ ), and tumour necrosis factor alpha (TNF- $\alpha$ ), which are mainly observed in ICU patients rather than in non-ICU patients $(33,44-49)$. This signifies a cytokine storm characterised by an abnormal overreaction of the body's immune system that causes a loss of communication between the infected cells and the host immune defence mechanism. Cytokine storm triggers severe inflammation and infiltration of neutrophils, macrophages, and $\mathrm{T}$ cells that may damage several tissues leading to multi-organ failure (50). Carveli et al. (51) demonstrated an association between COVID-19 mediated inflammation and activation of the C5 complement factor with its receptor called complement component C51 receptor (C5AR1). C5AR1 or C5a is a G-protein coupled receptor that modulates inflammatory response by activating neutrophils and monocytes to the site of damage.

\section{Invasion of SARS-CoV-2 in Secondary Organs}

ACE2 is widely expressed in a heterogeneous population of systemic cells (Figure 2), making it possible for SARS-CoV-2 to damage several systemic tissues leading to various clinical phenotypes that result in multi-organ dysfunction (Figure 2) (52-61). A high level of ACE2 in nasal epithelial cells correlates with increased viral load, especially in the early stages of SARS-CoV-2 infection (62). This may explain the accuracy of nasal and nasopharynx aspirates for SARS-CoV-2 diagnosis (62). The highest viral load was reported in the olfactory epithelium, suggesting damage in the supporting cells $(61,63-66)$. Although ACE2 level is low in the capillary endothelial cells of the cerebral circulation, circumstantial evidence suggests that SARS-CoV-2 may access these cells by crossing the blood-brain barrier, as demonstrated by in vitro studies. This may involve unknown indirect mechanisms that may be responsible for clinical manifestation (examples are anosmia, ageusia, and altered mental status) and neurological complications that have been observed in critical cases of COVID-19 infections (Figure 2) (67-73).

ACE2 and TMPRSS2 are also expressed in cardiomyocytes, cholangiocytes, hepatocytes, and enterocytes, suggesting potential targets for SARS-CoV-2 infection (60, 74-76). ACE2 synergises with the RAAS to regulate angiotensin to balance the normal function of the cardiovascular system $(77,78)$. Upon SARS-CoV-2 infection, ACE2 is suppressed and fails to counteract the vasoconstrictive and pro-inflammatory function of the RAAS to balance the system. This may lead to increased vascular permeability, tissue oedema/damage, and systemic microcirculatory dysfunction associated with cardiovascular-related disease (79). Approximately $50 \%$ of COVID-19 hospitalised patients exhibit abnormal levels of alanine transaminase (ALT) and aspartic transaminase (AST), slightly elevated level of bilirubin, higher alveolar-arterial oxygen gradient (A-aDO2)/gamma-glutamyl transferase (GGT), and hypoalbuminemia that suggests hepatic damage (80-82). Elevated levels of ALT (7590 U/L) and AST (1445 U/L) were almost doubled in severe/critical cases as relative to mild/moderate cases, and correlate with nausea, vomiting, and anorexia (83-85). In addition, a subgroup of COVID-19 patients present with darkened faces and pigmentation $(86,87)$. This may suggest abnormal liver function probably from failing to metabolise oestrogen, increased iron level, and melanin secretion as well as adrenocortical hypofunction associated with hepatic injury (88-91).

Zhao et al. (92), demonstrated that SARS-CoV-2 infection triggers direct cholangiocytes damage by perturbing the barrier and bile acid transporting functions of cholangiocytes via abnormal regulation of solute carrier family 10-member 2 (SLC10A2) gene and cystic fibrosis transmembrane conductance regulator (CFTR) gene, resulting in bile acid accumulation and consequent hepatic injury aggravation. Mechanisms associated with COVID-19-related hypoxia, antiviral drugs/incorrect drug dosage, and use of herbs or traditional medicines to counteract COVID-19 effects may also participate in liver injury (93-99). Numerous studies have reported successful isolation of SARS-COV-2 from faecal/stool samples of COVID-19 patients with and without inflammatory bowel disease (IBD) (100-103). Interestingly, in some COVID-19 cases, the faecal viral load was even higher $\left(10^{7}\right.$ copies/g) than in pharyngeal swabs $(101,104)$. This observation disputes the pharyngeal infection as the source of faecal viral RNA and supports the theory of enteric infection of SARS-CoV-2 $(101,104)$. An elevated level of faecal calprotectin, largely expressed by neutrophils and a reliable faecal biomarker of intestinal inflammation, has been reported in COVID-19 patients with diarrhoea as compared to patients without diarrhoea (105).

It has been demonstrated that nephrons, undifferentiated spermatogonia, testicular Sertoli, and Leydig cells express a considerable abundance of ACE2 receptor expression, making the kidney and testes further potential SARS-CoV-2 reservoirs (106, 107). Renal damage in cases with no underlying renal conditions suggested SARS-CoV-2 as the underlying cause, and this was marked by abnormal blood work and increased levels of proteins in the urine. Lengthy hospitalisation stays, acute kidney injury (AKI), and increased mortality were the most common consequences of severe or critical cases of COVID-19 (107-113). COVID-19 causes severe physiologic and neurological stress, which may release increased stress hormone and alter testosterone levels. Testes play an important role in regulating the hypothalamic-pituitary-testicular (HPT) axis, which governs the male reproductive hormonal cascade (114). HPT axis endocrinologically links testes to the brain by gonadotropins (luteinising hormone-LH and follicle-stimulating hormone-FSH) and testosterone. LH and FSH that normally activate Leydig and Sertoli cells, respectively, are altered in COVID-19 patients, and this is hypothesised to be due to imbalances in testosterone production (115-118). Levels of LH seem to increase in male patients with severe COVID-19 leading to abnormal FSH/LH ratios $(115,116)$.

A recent case report of semen analysis for in vitro fertilization procedure revealed that mild COVID-19 infection in men could result in long-term alterations in sperm morphology and sperm 


\section{ORGAN<smiles>[O]</smiles><smiles>c1ccc(C23CC4CC(C2)C(C4)C3)cc1</smiles> \\ BRAIN \\ CLINICAL MANIFESTATION \& MARKERS \\ Clinical Manifestation:delirium; ataxia; fatigue; ageusia; anosmia; altered mental status. Markers: $\mathrm{N}$-acetyl aspartate reduction; choline, lactate and myo-inositol elevation.}
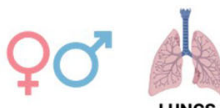

LUNGS
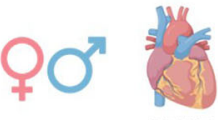

HEART
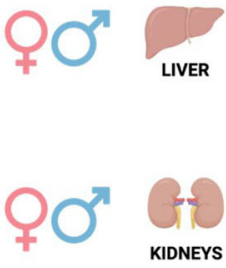

KIDNEYS

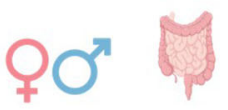

INTESTINES

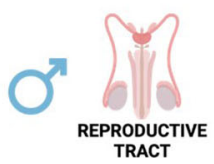

Cardiomyocytes

\section{Cholangiocytes} Bile Duct Cells
Hepatocytes

Kidney cells

Clinical Manifestation:fever; shortness of breath; cough; vomiting; ageusia; anosmia. Markers: D-dimer elevation; lymphopenia.

Clinical Manifestation:fever; shortness of breath; cough; vomiting; ageusia; anosmia. creatinine kinase; IL-1 1 IL-6, IFN-y, IL-4 and IL-10. serum levels elevated.

Clinical Manifestation:abdominal pain and swelling; fatigue; nausea; vomiting Markers: ALT, AST and bilirubin elevated levels: A-aDO2 and GGT; hypoalbuminemia lympocytopenia.

Clinical Manifestation:fever; shortness of breath; cough; fatigue; vomiting; ageusia; anosmia.

Markers: blood and protein levels elevated in the urine.

Epithelial cells (e.g enterocytes) Goblet \& ciliated columnar cells

Spermatogonia Sertoli cells Leidig cells

\section{Clinical Manifestation:diarrhoea; nausea; vomiting; anorexia; abdominal pain. Markers: faecal calprotectin; faecal detection of SARS-CoV2.} Markers: Troponins; myocardial-derived
POSSIBLE MECHANISMS \& COMPLICATIONS

Mechanism(s): ACE2 expression; hypoxia; neuronal inflammation and injury; demyelination; metabolic disruption. Complication(s): acute ischemic stroke; encephalopathy; brain haemorrhage; memory loss or cognitive impairment.

Mechanism(s): ACE2 expression; hypoxia; cytokine storm; metabolic disruption

Complication(s): pneumonia; acute respiratory distress syndrome; viral sepsis; kidney failure.

Mechanism(s): ACE2 expression; direct heart muscle infectoin and inflammation; pre-existing heart conditions; hypoaxemia; thrombosis; underlying metabolic disruption.

Complication(s): myocarditis; cardiomyopathy; cardiac failure.

Mechanism(s): ACE2 expression; direct infection injury; increased systemic inflammation; cirrhosis -associated immune function; coagulopathy; intestinal dysbiosis; pre-existing conditions; COVID-19 drug toxicity.

Complication(s): encephalopathy; ascites; hypercoagulation; liver injury; defective vaccine response; acute or chronic liver failure; respiratory failure

Mechanism(s): ACE2 expression; direct kidney infection and damage; increased thrombosis; microinflammation; hypoxia; cytokine storm.

Complication(s):acute tubular necrosis with septic shock; acute kidney injury.

Mechanism(s): ACE2 expression; direct infection; gut dysbiosis increased gut leakiness; disruption of tryptophan absorption; systemic inflammatory response; cytokine storm. Complication(s): acute haemorrhagic colitis.
Mechanism(s):ACE2 expression; direct infection and injury; blood circulation pathways (e.g. coagulopathy); neuronal pathways; cytokine storm.

Complication(s): intestinal oedema and congestion; impaired spermatogenesis.

FIGURE 2 Potential underlying mechanisms of SARS-CoV2 invasion and multi-organ induced damage. Inflammation mediated by SARS-CoV-2 infection and its primary receptor ACE2 drive multi-organ failure in severe COVID-19 cases. ACE2 is widely expressed in multiple organs, and its suppression may aggravate COVID-19 severity and negatively impacts multiple organs via regulation of RAS. Moreover, this leads to severe cases of COVID-19 that are often associated with ARDS and increased mortality rate, partially mediated by the overproduction of pro-inflammatory cytokines (cytokine storm). Cytokine storm results from increased levels of inflammatory mediators, endothelial dysfunction, coagulation abnormalities, and infiltration of inflammatory cells into the organs. This may be characterised by elevated levels of interleukin-6 (IL-6), nuclear factor kappa B (NFKB), and tumour necrosis factor-alpha (TNF $\alpha$ ) released from SARS-CoV-2infected macrophages and monocytes. The involvement of different organs in severe patients is characterised by multi-organ failure and a broad spectrum of haematological abnormalities and neurological disorders that lengthen the hospitalisation duration and increase mortality. The most important mechanisms are related to the direct and indirect pathogenic features of SARS-CoV2 infection. (Created with BioRender.com). ACE2, Angiotensin I-converting enzyme-2; AoDO2, First alveolar-arterial oxygen gradient; ALT, Alanine aminotransferase; AST, Aspartate aminotransferase; IFN- $\gamma$, Interferon-gamma; IL-1 $\beta$, Interleukin- $1 \beta$; IL-4/6/10, Interleukin- 4/6/10; TNF- $\alpha$, Tumour necrosis factor-alpha; MCP-1, Monocyte chemoattractant protein-1.

DNA integrity that may ultimately lead to male infertility (119). It was previously thought that the sperm parameters would take 70 - 90 days to return to their basal state after recovering from the infection. However, this published case has shown that this can take a much longer time of $>4$ months (119). Although these findings are based largely on case studies and lack further validation, it is plausible to hypothesize that increased risk of infertility as a COVID-19 long-term complication, especially in young men, will be observed after the pandemic. Therefore, more studies are needed to determine the negative impact of COVID19 in a large cohort of infected males with varying severity of disease during infection and after recovery.

\section{THE ROLE OF EPIGENETICS IN INFECTION SUSCEPTIBILITY: X- CHROMOSOME INACTIVATION AND COVID-19}

In terms of Betacoronavirus (SARS-CoV-2, severe acute respiratory syndrome coronavirus/SARS-CoV and Middle East respiratory coronavirus/MERS), men usually experience severe infections complicated with poorer clinical outcomes than women (120-124). It was observed that SARS-CoV-1 infected males had a significantly $(21.9 \%, \mathrm{p}<0.0001)$ higher case fatality rate than females (13.2\%) with a relative risk of 1.66 
(95\% confidence interval (CI): 1.35, 2.05) before age adjustment and 1.62 (95\% CI: 1.21, 2.16) after adjustment (120). Peckham et al. (123), demonstrated through a meta-analysis of 3,111,714 reported global COVID-19 cases that males have almost three times the odds of requiring ICU admission ( $\mathrm{OR}=2.84 ; 95 \%$ $\mathrm{CI}=2.06,3.92)$ and higher odds of fatality $(\mathrm{OR}=1.39 ; 95 \%$ $\mathrm{CI}=1.31,1.47)$ compared to females. X-chromosome inactivation (XCI) may explain some of the disparities in infection susceptibility (Figure 3). As an epigenetic hallmark of normal human development, XCI is regulated by a progressive and stepwise epigenetic phenomenon that ensures an equal dosage compensation of the $\mathrm{X}$-chromosome encoded genes expression level between females and males $(125,126)$. XCI is regulated by the $\mathrm{X}$-inactivation centre (XIC) and established by long non-coding $\mathrm{X}$ inactive specific transcript (Xist) RNA through several heterochromatin changes as largely demonstrated by seminal work conducted by the Brockdorff lab $(127,128)$. The suppression of $\mathrm{X}$-linked genes through recruitment of the PRCs is a common XCI feature (129). Acquisition of histone deacetylase 3 (HDAC3) and H2A by adding a single ubiquitin group to lysine-119 (H2AK119) are the earliest repressive epigenetic marks required for efficient XCI. $\mathrm{H} 3 \mathrm{~K} 27 \mathrm{me} 3$, a transcriptional silence mark that is catalysed by PRC2-EZH2 for inactive heterochromatin, is enriched and later spread at the promoters of silenced X-linked genes for long-term stable XCI maintenance $(129,130)$.

Notably, for counteracting invading pathogens, the Xchromosome is enriched with many immune-related genes and regulatory elements that activate host immune defence mechanisms (131). While this may increase women's susceptibility to autoimmune disease, it may also provide them with immunological and survival advantages against pathogen insults (132). Females have two copies of X-chromosome (XX), and one becomes randomly and permanently silenced during embryogenesis through XCI $(125,126)$. An inactivated chromosome is called a Barr body or sex chromatin (Figure 3). Some genes located in the silenced X-chromosome may escape XCI and remain expressed to perform their normal activities (133). Fortunately for women, these XCI skewing genes/escapees may lead to an elevated level and high immune responsiveness of such genes (134). Subsequently, this results in double and exclusive protection for women against defective $\mathrm{X}$ linked genes and infections relative to men (Figure 3). As a result of having a single copy of X-chromosome (XY), males are at high risk of X-linked or sex-linked disorders (134), and this may explain why males tend to suffer more severe cases of COVID$19 /$ other infections and fatal complications than females. Sex different effects in COVID-19 may be attributable to various external risk factors that are more prevalent in men versus women (135-140). Comorbidities such as cancer, heart failure, hypertension, diabetes, obesity and chronic obstructive pulmonary disease coupled with behavioural factors including smoking and alcohol consumption are generally increased in males than females, and these have been shown to correlate with poor clinical outcomes, increased risk of ICU admission and fatalities in COVID-19 infected patients (135-138, 140, 141). Men have been shown to have an increased level of circulating plasma ACE2 receptor, the primary receptor that enables SARS-
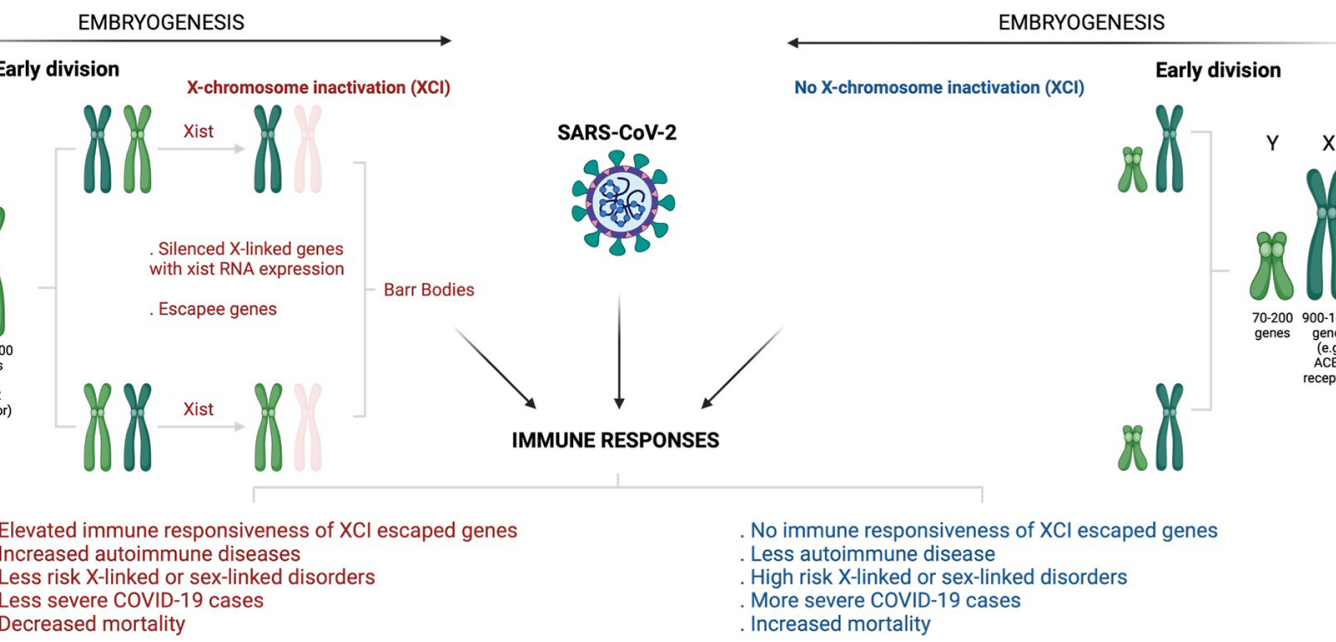

No immune responsiveness of $\mathrm{XCl}$ escaped genes

Less autoimmune disease

High risk X-linked or sex-linked disorders

More severe COVID-19 cases

Increased mortality

FIGURE 3 | Overview of sex-based differences in the immune response to COVID-19. The diagram shows how X-chromosome inactivation escapee genes may underlie sex bias differences in COVID-infection, severity, and mortality. Sex-bias differences in COVID-19 may be linked to ACE2, the primary receptor that enables SARS-CoV-2 infection. Having double X-chromosomes protects women against increased susceptibility to COVID-19 infection and associated severe complications as compared to men who have just a single $\mathrm{X}$-chromosome. ACE2 is an X-chromosome-linked gene that escapes $\mathrm{X}$-inactivation, a phenomenon that suppresses gene transcription from one of the two $X$ chromosomes in female mammalian cells to balance expression dosage between $X X$ females and $X Y$ males. This means that women have twice more genetic instructions to transcribe ACE2 and many more X-chromosome-linked immunoregulatory genes that protect women from increased COVID-19 susceptibility and associated severe complications. (Created with BioRender.com). ACE2, Angiotensin I-converting enzyme-2; COVID -19, Coronavirus disease 2019; SARS-CoV-2, Severe acute respiratory syndrome coronavirus 2; XCl, X-chromosome inactivation; XIST, X-inactive specific transcript. 
CoV-2 attachment and infection $(138,139,142)$. Using a highthroughput multiplex immunoassay based on a proprietary proximity extension assay (PEA) technology, Sama et al. (141) measured the ACE2 concentration in index cohort of 1485 males and 537 females with COVID-19 and heart failure, and found that the mean plasma concentration of ACE2 was higher by 5.38 in males compared with females $(5.09, P<0.001)$. This was also supported by a validation cohort that exhibited increased 5.46 ACE2 plasma concentration in males compared with 5.16 in females patients $(P<0.001)$ (141). A separate single center population-based study of 5457 Icelanders demonstrated altered serum levels of ACE2 in males, smokers and diabetes or obese patients, and this was associated with productive SARS-CoV-2 infection and severe clinical outcome (142). The expression levels of ACE2 receptor was found to be enhanced in the lungs in response to active smoking, diabetes and hypertension, explaining an increased susceptibility and severity to COVID-19 infection (138, $139,142)$.

Gene expression regulation of ACE2 and other X-chromosome linked genes, including Toll-like receptors (TLRs), CD40 ligand (CD40L), and Forkhead box P3 (FOXP3)/Scurfin, expressed upon SARS-CoV-2 infection, may play a critical role in COVID-19 pathogenesis and severity. Following viral entry, SARS-CoV-2 triggers the activation of the RNA-based pathogen sensors such as TLR3, TLR4, TLR7, and retinoic acid-inducible gene-I-like receptors (RIG-I), which complex with a melanomadifferentiation associated 5 (MDA-5) to establish a frontline defence mechanism (143). This complex is epigenetically subverted to induce abnormally elevated levels of interferons (IFNs) and pro-inflammatory cytokines, such as tumour necrosis factor alpha (TNF- $\alpha$ ) and interleukins (ILs), associated with critically ill and ICU admission of COVID-19 patients $(131,144)$.

Dai et al. (145), through integrated bioinformatics analysis revealed an upregulation of structural maintenance of chromosomes flexible hinge domain containing 1 (SMCHD1) in COVID-19 patients, suggesting that it may be involved in the epigenetic control of ACE2 receptor, and thus COVID-19 pathogenesis. It is not surprising that SMCHD1 is linked to ACE2 receptor regulation, as it is an essential protein in XCI. Mouse studies have demonstrated that homozygous nonsense mutations in the Smchd1 gene cause XCI defect that leads to female-specific embryonic lethality $(146,147)$. Gendrel et al. (125), demonstrated that a late step Smchd1 gene recruitment to $\mathrm{XCI}$ in female XX embryonic stem cells establishes DNA methylation of $\mathrm{CpG}$ islands, preferably via Dnmt3b gene and histone mark H3K27me3 for long-term maintenance of gene silencing. An SMCHD1-dependent pathway may explain the data of Mudersbach et al. (148), demonstrating that TNF- $\alpha$ suppresses ACE2 mRNA and its protein expression in endothelial cells via hypermethylation by DNMTs, including DNMT3b. It has been suggested that suppression of TNF- $\alpha$ mediated ACE2 mRNA via epigenetic inhibitors may reduce SARS-CoV-2 viral replication, leading to anti-inflammatory effects associated with quicker healing and resolution of COVID-19-related complications (148). SARS-CoV-2 genome encodes mRNA Cap 2'-O-Methyltransferase (2-O-MTase), another epigenetic phenomenon that deposits a methyl group at the 2 '-O position of the first nucleotide adjacent to the cap structure at the 5' end of the RNA (149-152). RNA-based viruses often use this mechanism to their advantage to escape immune surveillance. It might be tempting to speculate that drugs targeting these epigenetic marks and preventing immune evasion may also be important in fighting COVID-19 infection.

\section{POSSIBLE EPIGENETIC DYNAMICS IN COVID-19 INFECTION}

Li et al. (153) have demonstrated in a murine mouse model with the human ACE2 (hACE2) transgene that SARS-CoV-2 induces epigenetic-mediated metabolic reprogramming and alterations in both local and systemic sites of infection. These alterations are associated with systemic lethality that mirrors human COVID19 clinical phenotypes, suggesting an epigenetic role in COVID19 pathogenesis. Below, we discuss epigenetic marks and alterations that we hypothesize may play a role in ACE2 receptor regulation and COVID-19 pathogenesis/treatment.

\section{Writing of DNA Methylation and Role of DNMTs}

DNMT1, DNMT3A, DNMT3B, and DNMT3L are family of DNMTs that write or deposit methylation on DNA leading to hypermethylation, read by MBDs to mainly suppress gene transcription (Figure 1) $(4,154)$. DNMT1 binds to and methylates hemi-methylated $\mathrm{CpG}$ sites to ensure stable maintenance of DNA methylation (4). DNMT 3A and 3B are de novo methyltransferases that mainly lead to transcriptional repression through the establishment of non-CpG methylation, an emerging epigenetic mark that defines brain tissue-specific patterns of gene transcription (155-159). DNMT3L is catalytically inactive and serves as a cofactor for DNMT $3 \mathrm{~A}$ and $3 \mathrm{~B}(160,161)$.

Although DNA methylation patterns are erased and deposited through successive normal developmental stages and cell differentiation, they also occur in the form of epigenetic memory in stem cells, and in communicable and non-communicable diseases, reviewed in (162). Most importantly, various epigenetic phenomena triggered in response to raging viral replication are usually hijacked by the same targeted virus to alter the protective immunoregulatory mechanisms for survival and propagation, reviewed in (163). For instance, during infection with hepatitis B virus (HBV), DNMTs are upregulated in response to productive viral replication mediated by the host-viral interaction as part of host immune defence mechanisms, also reviewed in (164). In the long run, the same DNA methylation machineries may start hypermethylating $\mathrm{CpG}$ island promoters that overlap with host-viral integration sites leading to alteration in the transcription of genes, including immunoregulators and tumour suppressors that are critical to carcinogenesis (164). COVID-19 related airborne respiratory infections such as the Middle East respiratory syndrome-CoV (MERS-CoV) and avian influenza (H5N1) have also been shown to exploit DNA methylators and 
histone modifiers to suppress immunoregulators such as type 1 IFN- $\gamma$-responsive genes. These genes include class II, major histocompatibility complex, transactivator (CTIIA), antigen peptide transporter 2 (TAP2), and protein disulfide-isomerase A3 (PDIA3) (165). Abnormal regulation of these genes impedes the host immune system to fight infections effectively (166). This suggests that various epigenetic reprogramming phenomena may also occur during COVID-19 infection (167).

Mice transfected with hACE2 and subsequently infected with SARS-CoV-2 have been used to gain insights into epigenetic changes that drive cardiac injury in COVID-19 patients (153, 168). Li and colleagues identified 172 differentially methylated $\mathrm{CpG}$ sites in the hearts of SARS-CoV-2-infected mice compared with controls (153). Two genes, paternally expressed gene 10 (Peg10) and endothelin-converting enzyme 1 (ECE1), show high levels of differential methylation in SARS-CoV-2 mice bearing hACE2 compared with controls. For the Peg10 gene, a hypomethylation pattern consistent with higher expression of the Peg10 gene in hearts was seen. The loss of function of the Peg10 gene is known to result in early embryonic death (169). Peg10 gene also regulates cellular proliferation and viral replication through binding to the viral transcription regulators (170). SARS$\mathrm{CoV}-2$ infection was associated with increased methylation of the $E C E 1$ gene, the product that regulates proteolysis of endothelin precursors to form biologically active peptides (171). Loss of function of the ECE1 gene is associated with cardiac defects, generalized oedema, and autonomic dysfunction (172). In another study, blood samples from acute SARS-CoV-2 infection versus healthy controls blood samples exhibited $28 \%$ of hypermethylated regions (173). Hypermethylated regions comprised of more than 5 consecutive differentially methylated CpG sites. It is not surprising that studies with SARS-CoV-1 and MERS also detected differentially methylated CpG sites, and found to be located in the promoter regions encoding genes involved in interferon and antigen presenting cells stimulation (174). This supported a recent study that identified $>40 \mathrm{CpG}$ sites encoding genes serving similar purposes, suggesting the role of DNA methylation influencing COVID-19 progression and target for epigenetic therapy (175).

Activation of the immunoregulatory cytoplasmic transcription factor aryl hydrocarbon receptor (AHR) may also result in hypermethylation that contributes to COVID-19 pathogenesis. The AHR has been identified as a host factor for Zika and Dengue viruses, and its inhibition was associated with significantly reduced viral replication and amelioration in the disease pathology (176-178).

It has been shown that the AHR becomes activated upon SARS-CoV-2 infection (178), and that it impacts SARS-CoV2 antiviral immunity and pathogenesis, promoting a proinflammatory response and participating in the severity of COVID-19 (178). Furthermore, it has been postulated that AHR activation may be the culprit behind the COVID-19mediated cytokine storm $(145,178,179)$. RNA-Seq analysis of $\mathrm{CoV}$-infected cells unveils an upregulation of the AHR and its target genes, including AHRR and CYP1A1 (177). Kynurenic acid, a product of normal metabolism of L-tryptophan, and a potent endogenous AHR ligand, has also been shown to be elevated in response to COVID-19 $(139,180)$. This correlated with cytokine storm, age and low levels of $\mathrm{T}$-cell responses, especially in males as compared to female patients, hinting for a sex-specific link to immune response and COVID-19 clinical outcome (139). Curiously, activation of the AHR has been associated with hypermethylation in acute lymphoblastic leukaemia (ALL) in vitro. When demethylated by methylation inhibitor zebularine, AHR-related methylation inhibition restored normal cells phenotype and prevented tumorigenesis (181). In another study, AHR activation resulted in epigenetic alteration of Foxp3 and IL-17 expression and consequently attenuated colitis (182). Recently, Jiadi et al. (183), have shown that macaques infected with SARS-CoV-2 modulation of the AHR upregulates the expression of ACE2 by binding to its promoter regions, and this is accompanied by aggressive disease. Consequently, if the AHR becomes hypermethylated, as shown in other pathologies, the level of ACE2 may also be silenced through the same methylation. This may disrupt the inhibitory mechanisms regulated by ACE inhibitors or other RAAS blockers leading to the aggressiveness of underlying cardiovascular diseases (e.g., hypertension) that have been reported in severe/critical cases of COVID-19 infection.

Interestingly, the AHR also regulates the expression of NOD-, LRR- and pyrin domain-containing protein 3 (NLRP3), that may also be epigenetically regulated $(184,185)$. Castro de Moura et al., revealed a strong correlation between COVID-19 clinical severity and DNA methylation of $44 \mathrm{CpG}$ sites with $>50 \%$ of these located in 20 promoters of annotated coding genes including Absent in Melanoma 2 (AIM2) and major histocompatibility class $1 C$ (HLAC) (175). AIM2, similarly to the NLRP3, is part of the inflammasome complex (186). The inflammasome is involved in caspase-1 cleavage, trigger of gasdermin $\mathrm{D}$-mediated pyroptotic cell death and release of pro-inflammatory cytokines IL-1 $\beta$ and IL-18 in response to pathogens' insult, reviewed in $(187,188)$. Altered levels of IL$1 \beta$ and IL-18 cytokines were observed in COVID-19, as it does in several male infertility-related disorders such as varicocele (49, $111,189)$, suggesting that NLRP3 may also be activated upon COVID-19 infection. This notion is supported by the study of $\mathrm{Su}$ et al. (190), that demonstrated that upregulation of calciumsensing receptor (CaSR) activates the NLRP3 pathway in testicular macrophages and impairs testosterone synthesis in a uropathogenic Escherichia Coli (UPEC) rat orchitis model.

Chronic infections such as $\mathrm{HBV}$, hepatitis $\mathrm{C}$ virus (HCV), and human immunodeficiency virus (HIV) have been demonstrated to infect sperm cells and trigger oxidative stress. Subsequently, this activates histone modifications leading to long-term effects on male fertility parameters such as sperm integrity, count, motility, and morphology. During normal differentiation, sperm cells' genome undergoes successive rounds of epigenetics marks to ensure proper spermatogenesis and spermiogenesis (191). More than $85 \%$ of human mature sperm cells' DNA is bound to protamines. Protamines are sperm-specific basic nuclear proteins that take over the histones' position and function to package the sperm DNA for 
compaction necessary for sperm motility (192). In the late stages of spermatogenesis, sperm cells' genome becomes dramatically reorganised and globally hyperacetylated to remove and replace histones with protamines. This phenomenon essentially erases the epigenetic modifiers laid out through histone modifications. It preserves the paternal genome by protecting it from extracellular stressors and harmful effects of the oocyte during fertilisation (192). An altered protamine ratio or histone content or distribution in sperm is a sign of aberrant chromatin packaging, associated with increased susceptibility to DNA damage or abnormal epigenetic marking that may lead to male infertility. Ma et al. (108), have detected SARS-CoV-2 in the testis' biopsies of COVID-19 patients. Immunohistochemistry analysis revealed a significant increase in spermatogenic epithelial shedding in the deceased patients with critical cases of COVID-19, which was accompanied by thinning of seminiferous tubules (193). Inflammation of the epididymis and/or testicle was associated with old age $(>80 \mathrm{yrs})$ and severe or critical cases of COVID-19 (P = .037) (107). More than $20 \%$ of recovered patients who previously had children through natural birth exhibited autoimmune orchitis. This was indicated by observed oligospermia, leukocytospermia, elevated sperm phagocytic CD3+/CD68+ immune responses in testes/ epididymis and apoptotic cells relative to age-matched control males (193). In some cases, tocilizumab was administered in response to a progressive worsening of oxygenation, and blood biochemistry tests revealed an elevation of lactate dehydrogenase to $1213 \mathrm{U} / \mathrm{l}, \mathrm{D}$-dimer to $1150 \mathrm{ng} / \mathrm{ml}$, and CRP to $23.80 \mathrm{mg} / \mathrm{dl}$. Impaired spermatogenesis and increased apoptotic cells may be attributable to COVID-19-induced histone modifications associated with elevated CRP and fever that perturbed the optimum testicular temperature $\left(2-4{ }^{\circ} \mathrm{C}\right.$ below the average body temperature) (194). Moreover, extensive germ cell destruction, as demonstrated by the TUNEL assay, may have also been a contributing factor.

\section{Erasing of DNA Methylation: Role of TETs}

TETs are regarded as erasers of DNA methylation, reviewed in (195). They actively or passively demethylate DNA methylation by removing the 5 -methylcytosine mark. TETs oxidise 5methylcytosine to generate 5-hydroxymethylcytosine (5-hmc), 5-formylcytosine (5-fc), and 5-carboxycytosine (196-198). 5$\mathrm{hmc}$ is a stable epigenetic mark that is highly abundant in the brain, liver, and stem cells, and it is crucial for neurogenesis and hepatocellular carcinoma (HCC) $(199,200)$. TETs are prominent regulators of immune cells. For example, Tet- 2 mediates T-cell differentiation and synergises with Tet-3 to modulate the expression of Foxp3, a transcription factor responsible for $\mathrm{T}$ cells development (201). Tet-deficient mice CD4-T cells exhibited impaired Th1/2/17 differentiation and cytokine production in lymphocytic choriomeningitis virus infection, supporting a critical role of Tet-2 in infections (202). In other studies, loss of Tet $2 / 3$ resulted in an antigen-driven expansion of various immune cells and rapidly developed aggressive disease phenotype $(203,204)$. Moreover, combined deletion of Tet $2 / 3$ in mice exhibited impaired Treg cell differentiation. This was accompanied by DNA hypermethylation of various Treg-specific demethylated regions (TSDRs) within the Foxp3 locus that resulted in aberrant Foxp3 expression (205, 206). TNFs and ILs, important cytokine storm elevated markers observed in severe or critical cases of COVID-19, are known to induce DNA demethylation via TETs (207-210). IL-1 $\beta$ and TNF- $\alpha$ modulate the global hydroxymethylation by activating TETs and iso-citrate dehydrogenases in the genomic DNA and specific locus in matrix metalloproteinase (MMP) promoter region in human OA chondrocytes (211).

In severe COVID-19 pneumonia cases, abnormal upregulation of T-cell proliferation, activation, and cytotoxicity was noted at the late phase of infection, suggesting an underlying perturbation resulting in the loss of an inhibitory role Tregs (212). Mohebbi et al. (210), have shown that CD4+ FoxP3+ CD25+ T cells expression level is significantly suppressed in hospitalised COVID-19 patients and led to an elevated level of IL-6. Given this evidence, it is intriguing to suggest this aberrant hyperactivation of cytotoxic cells in COVID-19 may be attributable to Tet-2/3mediated epigenetic regulation of Tregs. Cell division occurring as a result of antigen and cytokine stimulation in response to COVID-19 infection may be the underlying mechanism for this epigenetic reprogramming. This may result in aberrant gene transcription, fatal inflammatory response, disease aggressiveness, and multiorgan disease phenotypes observed in severe and critical cases of COVID-19.

Abnormal production of the IFN and IFN- $\gamma$ correlate with slowly resolved COVID-19, and enhanced viral replication was also observed, as previously reported in other studies (213-215). This may also correlate with genetic variation of heat shock protein 70 (HSP70) or A1L (HSPA1L), which has been demonstrated to result in significantly higher plasma concentrations of TNF- $\alpha$ and IL- 6 and poor clinical outcomes after severe tissue injury from pathogens (216). Elevated levels of TNF- $\alpha$ and IL- 6 are associated with severe cases of COVID-19 and systemic inflammation, as well as HSPA1L gene upregulation via hypomethylation of its promoter regions in response to increased SARS-CoV-2 viral replication (217). HSPA1L hypomethylation is catalysed by the dramatically reduced DNA methyltransferases (DNMT 1 - 3), possibly via TETs and postulated to enable viral cell entry and protein synthesis $(217,218)$.

\section{Writing Histone Modification: Role of HATs and HMTs}

Histone lysine acetylation is catalysed by conserved histone acetyltransferases (HATs) and plays a crucial role in viral infections $(219,220)$. It facilitates the transfer of an acetyl functional group from acetyl coenzyme $A$ to the $\varepsilon$-amino group of the lysine residue at one end of the histone molecule on the chromatin. HATs alter the charge of various lysine residues within either $\mathrm{H} 3$ (histone acetylation at lysine 9, 14, 18 , and 23 , denoted as $\mathrm{H} 3 \mathrm{~K} 9 / 14 / 18 / 23 \mathrm{ac})$ or $\mathrm{H} 4$ (H4K5/8/12/ $16 \mathrm{ac})$, reviewed in (221-223). A positive charge from lysine becomes neutralised by a negative charge from a transferred molecule, reducing the binding affinity between histones and DNA. This alters the chromatin architecture by opening the chromatin and making it accessible to the transcription factors for active gene expression (221-223). MYST writes histone 
acetylation, adenoviral E1A-associated protein of $300 \mathrm{kDa} /$ CREB-binding protein (p300/CBP) and general control nonderepressible 5 (GCN5)-related N-acetyltransferases (GNATs) and read by bromodomains (BRD) and extra-terminal (BET) family of proteins $(221,222)$.

Histone $\mathrm{H} 3$ and $\mathrm{H} 4$ form a significant component of the host immune defence mechanism against pathogen insults and other hostile environments. In vitro studies with retroviral infected mouse embryonic fibroblasts have shown that histones are loaded rapidly on unintegrated retroviral DNA soon after infection $(219,220)$. Unintegrated retroviral DNA is typically weakly expressed, but in response to interaction with loaded histones, their expression may become dramatically increased by chromatin modifiers and promote persistent infection $(219,220)$. Several studies have shown that histones can be released into blood circulation during an infection as damage-associated molecular patterns (DAMPs) from apoptotic and damaged cells, eliciting an inflammatory stimulus (224-226). DAMPS interact with TLRs, and trigger TLR/myeloid differentiation factor 88 (MyD88)/NLRP3 pathways leading to activation of macrophages (227). This, in turn, can cause an accumulation of neutrophil infiltration and subsequent production of neutrophil extracellular traps (NETs) and reactive oxygen species (ROS) (227). Activation of TLR/MyD88/NLRP3 pathways has been upregulated in obese patients that are at high risk of severe COVID-19 infection (228). This suggests that activating these pathways by the DAMPs and histones loaded on viral proteins may be the mechanism underlying an excessive tissue inflammation and injury that correlates with multiple organ failure and increased mortality in COVID-19 infection.

Histones can also bind to complement component 5a (C5a) and CRP, which are proteins expressed by the liver in response to systemic inflammation (229-231). CRP is a regulatory factor for angiogenesis and thrombosis associated with cardiovascular disease (CVD), which is a risk factor for COVID-19 severe cases (232). An elevated level of C5a and CRP in COVID-19 infection is an indication of excessive inflammatory response in endothelial cells and tissue damage that correlates with aggravated disease or poor prognosis. Neutrophils play an important role in the early or later stages of severe cases of influenza A virus (IAV), and COVID-19 infection cases, where circulating cell-free histones are enriched and highly pro-inflammatory (233). Hsieh et al. (233) have shown that binding of histones $\mathrm{H} 4$ to CRP in neutrophils models infected with IAV blocks the H4-mediated neutrophil activation and potentiates neutrophil inflammatory response during infection (233). This data suggests that H4 may be part of the host protective mechanism during excessive pro-inflammatory response. However, in response to interaction with circulating virus through molecules such as $\mathrm{C} 5 \mathrm{a}$ and CRP, this mechanism may be hijacked by the virus for its replication advantage leading to tissue damage and fatal sequelae observed in COVID-19.

A case study of four unrelated young men who were critically ill with COVID-19 infection, and subjected to mechanical ventilation in the ICU, revealed nonsense and missense X-chromosomal TLR7 variants using whole-exome sequencing (213). This TLR7 variant mutation resulted in a unique loss of function from aberrant alteration of TLR7 mRNA expression and its downstream target genes. Interferons regulatory factor 7 (IRF7), interferon beta 1 (IFNB1), and interferon stimulated gene 15 (ISG15) are examples of genes associated with this TLR7 variant mutation. IRF7 becomes acetylated by HATs p300/CBP-associated factor (PCAF) and GCN5, and this usually impairs its binding activities leading to reduced IRF7 activity. PCAF acetylase complex and GCN5 are required for viral integration, and they have also been shown to be activated in influenza $A$ virus to negatively regulates the viral polymerase activity $(234,235)$. PCAF is also known as lysine acetyltransferase $2 \mathrm{~B}$ (KAT2B), a master regulator of TGF- $\beta$ signalling pathway that triggers CVD development when altered. The SARS-CoV-2 virus induces an aberrant and excessive TGF- $\beta$ mediated chronic immune reaction creating a switching from IgM to IgA1 and IgA2 immunoglobulins $(38,236)$. This, in turn, causes an increased pro-inflammatory response and severe disease activity that correlates with prolonged ICU COVID-19 cases and fatalities $(38,236)$. It is important to investigate the possible roles of PCAF and GCN5 activities in regulating TGF- $\beta$ and TLR7 signalling pathways in severe COVID-19 for novel treatments to ameliorate the severity and prevent COVID-19 fatalities.

Unlike histone acetylation, histone methylation does not modify any histone protein charge but deposits one or a set of methyl groups from S-adenosyl methionine (SAM) on the side chains of either $\mathrm{H} 3$ or $\mathrm{H} 4$ lysines or arginine (237). Histone methylation is catalysed by histone methyltransferases (HMTs) with various methylation sites (238). One of these HMTs is SET1B with H3K4me3 occupancy on open chromatin, and this recruits transcription factors for epigenetic transcriptional activation (239). This epigenetic tag has been shown to induce hypoxia, one of the emerging key drivers of COVID-19 pathogenesis and related fatalities. COVID-19 related-hypoxia manifests insufficient levels of oxygen supply in various tissues. SET1B activation is oxygen-dependent and facilitates hypoxia responses via site-specific histone methylation (240). In response to hypoxia, SET1B is recruited to the hypoxia-inducible transcription factor (HIF) promoter via HIF1 $\alpha$ and facilitates the expression of genes involved in angiogenesis (240), one of the clinical features of COVID-19 severity. HIF-related genes will be described further in a later section of histone demethylation.

\section{Erasing Histone Modification: Role of HDACs and LSDs/KDMs}

Histone acetylation and methylation are erased by HATs and lysine demethylases (KDMs)/lysine-specific demethylases (LSDs), respectively. The former result in a more condensed, closed, and transcriptionally silenced chromatin structure that is not accessible to transcription machineries (6-10). The latter blocks the recruitment or occupancy of transcriptional factors on the chromatin sites (9). The process is called histone lysine deacetylation or demethylation, and it associates with the repression of gene transcription. HDACs are grouped into four classes, including class I (HDACs 1 - 3 \& 8), class II (HDACs 4 -7, 9 \& 10), class III (Sirtuin 1 - 7) class IV (HDAC 11), reviewed in (241, 242). KDMs/LSDs include KDMs/LSDs $1-6$ with several families that act on different substrates for various cellular processes. 
Histone repression marks are common phenotypical features in viral infections and other diseases, such as cancer (243). Virusinduced cancers from HBV, HPV, and EBV hijack histone acetylation marks for viral survival and propagation, and various HDACs inhibitors have been shown to circumvent these effects and alleviate the disease (244-247). Sirtuin 1 (SIRT1) is a key epigenetic regulator of CVD, metabolic and age-related disease through interaction with nuclear transcription factor- $\kappa \mathrm{B}(\mathrm{NF}-\kappa \mathrm{B})$, a master regulator of inflammation activated by a signal transducer and activation of transcription 3 (STAT3) $(248,249)$. STAT3 becomes hyperactivated and impairs immune defence machineries that promote exacerbated inflammation and lymphocytopenia, leading to lung fibrosis and thrombosis, as demonstrated in severe COVID-19 cases (249). SIRT1 was also shown to interact with and modulate p53 activities to regulate viral replication in MERS-CoV and SARS-CoV infections (250, 251). Takahashi et al. (252), have recently shown that panobinostat, an inhibitor that counteracts HDACs effects, silenced the transcription of ACE2 receptor and $\mathrm{ABO}$ gene (gene encoding three blood group alleles) in cultured epithelial cell lines. This suggested a potential preventative drug against COVID-19 infection (252, 253). ACE2 is the primary host receptor for viral entry, whereas the $\mathrm{ABO}$ blood group system has been suspected to increase susceptibility for severe COVID-19 cases $(252,253)$. Related to this, Zhao et al. (254), have shown that blood group A individuals may be susceptible to COVID-19 infection, owing to the enrichment of group A antigen in respiratory cells (254).

Upregulation of HDACs by hypoxia was shown to be activated in response to a silence in hypoxia-responsive tumour suppressor genes $(255,256)$. These genes include HIF- $1 \alpha$ and vascular endothelial growth factor (VEGF), and their epigenetic-mediated alteration correlates with a dramatic increase of intussusceptive angiogenic features (255). A similar clinical phenotype was observed in the lungs of deceased COVID-19 patients, exhibiting distinctive pulmonary vascular pathophysiologic features in a background of perivascular inflammation and injury, as relative to those of influenza (257). VEGF is a prominent mediator of angiogenesis and is usually involved in wound healing (257). VEGF exerts its activities through VEGFR 1-3, which are targeted and negatively regulated by epigenetics alterations (258). VEGFR3 receptor has two ligands, VEGF-C and VEGF-D, which stimulate angiogenesis. Interestingly, serum levels of VEGF-D were found to be significantly elevated in ICU COVID-19 patients as compared to non-ICU patients, a novel biomarker to trace the progression of disease (258). Current research shows that VEGF and its associated receptors undergo histone deacetylation, suggesting them as potential epigenotherapy targets. It has previously been shown that histone deacetylase 4 (HDAC4) remodels neuronal morphology by altering the transcription signature of VEGF-D (259). Activation of HDAC2 suppresses inflammatory cytokines (e.g., IL-17, Figure 4) in pulmonary disease, and this with the disease onset and sometimes with prognosis (260-262). On another note, Ahmad et al. demonstrated that endothelial TLR/ MyD88 signalling is regulated by histone deacetylase 6 (HDAC6), contributing to alveolar remodelling architecture and pulmonary inflammation (263). Upregulation of TLR/MyD88 signalling pathway in association with elevated TNF- $\alpha$ and IL- 6 was reported in overweight and obese individuals as compared to lean individuals (263). In referral to this observation, Cuevas and coauthors have recently published a brief communication postulating and probing for a research study that upregulation of TLR/MyD88 signalling pathway may contribute to excessive and fatal proinflammatory cytokine storm especially in SARS-CoV-2 vulnerable obesity individuals (228). MyD88 was shown to establish and promote CD4 T-cells responses to control viral spread to the central nervous system (CNS) in coronavirusinduced encephalomyelitis (228). Any abnormal regulation of MyD88 signalling already existing in obese individuals and other co-morbidities may impact COVID-19 disease progression leading to more fatalities (228).

The widespread methylation of genes in SARS-CoV-2 infection is associated with the downregulation of genes involved in the regulation of the tricarboxylic acid (TCA) and mitochondrion electron transport chain (153). SARS-CoV-2-induced epigenetic alterations interfere with metabolic processes that are core to generating energy for the myocardium (153). The perturbed metabolic processes restrict the energy required for uncontrolled systemic inflammatory response leading to myocardial injury. Transcriptome analysis studies conducted from patients with hypertension and DM associated with severe COVID-19 cases revealed that ACE2 expression was potentially regulated synergistically by various histone marks such as histone acetyltransferase 1 (HAT1), HDAC2, and lysine demethylase $5 \mathrm{~B}$ (KDM5B) (264). KDM5B is a histone $\mathrm{H} 3 \mathrm{~K} 4 \mathrm{me} 2 / 3$ demethylase that is associated with therapeutic resistance in cancer (264). Hinohara et al. (264), demonstrated that inhibition of KDM5B increases sensitivity to endocrine therapy by modulating oestrogen receptor, suggesting the therapeutic potential of this epigenetic demethylating mark. Concerning viral infections, KDM5B was shown to suppress stimulator of interferon genes (STING), a cytosolic DNA sensor that activates downstream transcription factors signal transducer and activator of transcription 6 (STAT6), and interferon regulatory factor (IRF3) through TANK-binding kinase 1 (TBK1) (265). This, in turn, protects the host cells by eliciting an antiviral response and innate immune defence against intracellular pathogens and cancer (265). SARS-CoV proteins were shown to interact with STING and activate the STING-TRAF3-TBK1 complex leading to abnormal alteration and inhibition of type 1 IFN activities that may be associated with severe disease (266). $3 \mathrm{C}$-like (3CL), the main protease and regulator of viral replication for SARS-CoV-2, was shown to inhibit the activation of immune defence machinery by perturbing both RIG-I-like receptors (RLR) and cGAMP binds to stimulator of interferon genes (CGAS-STING) pathways in human lung cells, suggesting a mechanism that will enable the virus to replicate more efficiently during infection (267). Upregulation of STING and aberrant activities usually correlate with cytokine storm in older people and those who suffer from metabolic disorders (268-271). This may explain the increased COVID-19 severe cases in patients who are older, diabetic, and hypertensive. 


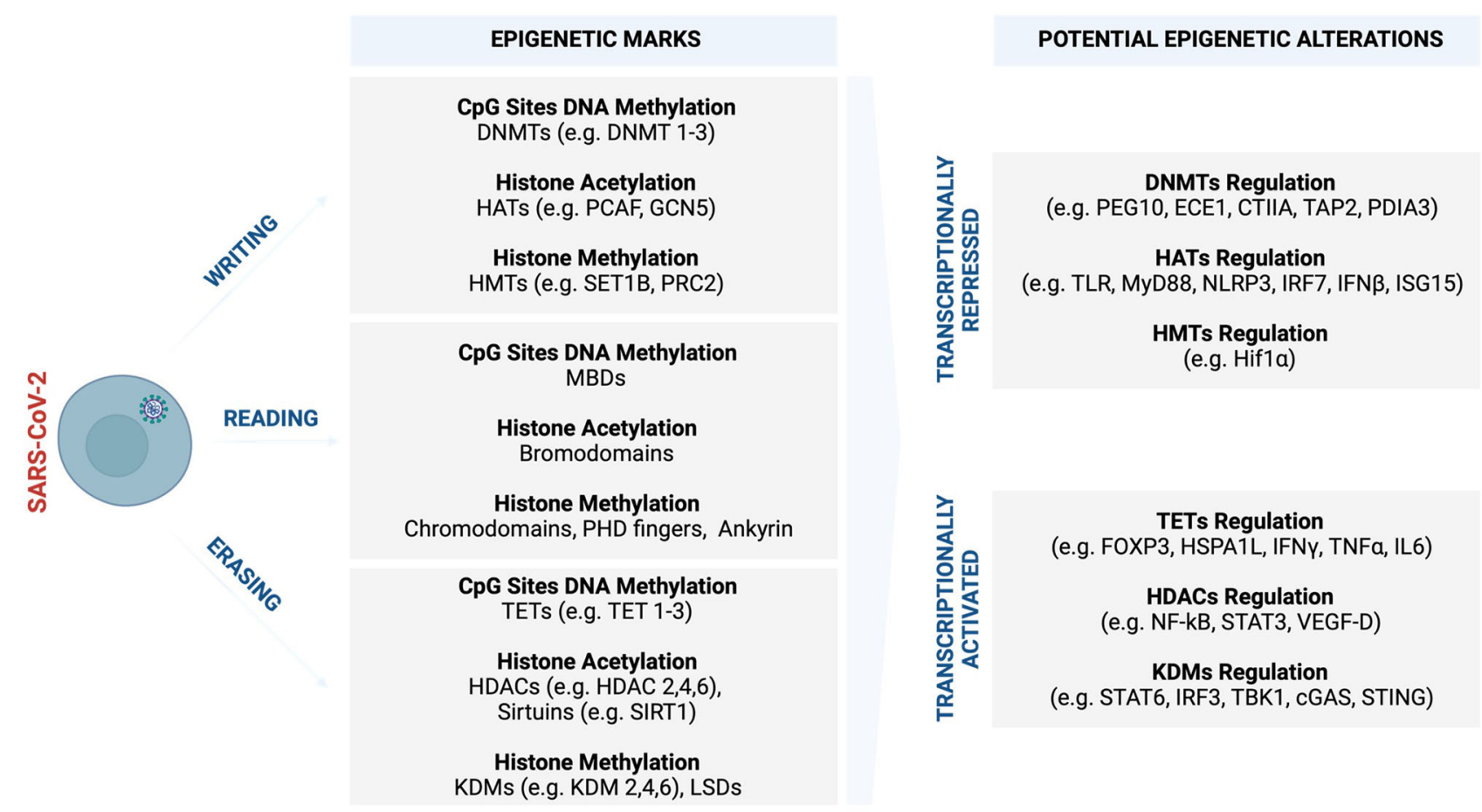

FIGURE 4 | Potential COVID-19 related epigenetic alterations and clinical implications. Like many other viruses, SARS-CoV-2 may trigger various epigenetic alterations such as global DNA methylation and histone modifications, which synergistically cooperate in influencing and driving the course of COVID-19 and sex-bias differences. In response to increased viral replication, the infected host cells may set off an epigenetic signature to antagonise the virus as part of innate immune defence machinery. Part of this epigenetic landscape may be subverted to benefit the virus and its propagation, leading to enhanced and systemic COVID-19 infection that promotes severe complications. (Created with BioRender.com). cGAS, Cyclic GMP-AMP synthase; CIITA, The major histocompatibility class (MHC) II transactivator; DNMTs, DNA methyltransferases; ECE1, endothelin Converting Enzyme 1; FOXP3, Forkhead box protein P3; GCN5, General control non-repressed 5 protein; HATs, Histone acetyltransferase; HDAC, Histone deacetylase; HIF$1 \alpha$, Hypoxia-inducible factor-1 $\alpha$; HSPA1L, Heat shock protein family A (Hsp70) member 1-like; IFN- $\gamma$, Interferon gamma; IFN- $\beta$, Interferon- $\beta$; IL-6, Interleukin- 6; IRF2, Interferon regulatory factor 2; IRF3, Interferon regulatory factor 3; ISG15, Interferon-stimulated gene 15; JmjC, Jumonji C; KDM, Histone lysine demethylases; LSD, Lysine-specific demethylases; MBDs, Methyl-CpG binding domains; MyD88, Myeloid differentiation factor 88; MLL, Mixed-lineage leukaemia; NF-kB, Nuclear factor kappa B; NLRP3, NOD-, LRR- and pyrin domain-containing protein 3; PDIA3, Protein disulfide isomerase family A member 3; PEG10, Paternally expressed gene 10; PHD, Plant homeodomain; PRC, Polycomb repressive complex; p300/CBP, p300 and cyclic AMP response element-binding protein; STAT-3, Signal transducer and activator of transcription-3; STAT-6, Signal transducer and activator of transcription-6; SET1, Suppressor of variegation 3-9, enhancer of zeste, trithorax 1; SIRT, Sirtuins; STING, Stimulator of interferon genes; TAP2, Transporter 2, ATP Binding Cassette Subfamily B Member; TBK1, Tank binding kinase 1; TET, Ten-eleven translocation; TLR, Toll-like receptors; TNF- $\alpha$, Tumour necrosis factor-alpha; UTX1, Ubiquitously transcribed tetratricopeptide repeat, X chromosome 1; VEGF-D, Vascular endothelial growth factor D.

\section{POTENTIAL OF EPIGENETIC DRUG TREATMENT IN COVID-19 INFECTION}

Given the above evidence, it is of great interest to determine the impact of various epigenetic marks in COVID-19-related severity and progression for their exploitation for future COVID-19 epigenetic therapy. Although other molecules and pathways (e.g. nuclear factor erythroid 2-related factor $2 / \mathrm{Nrf2}$ and NLRP3) could also be interesting to be mentioned and included in this section $(184,185,272)$, we decided to focus on the AHR due to its prominent roles in diverse diseases, including COVID-19. The AHR is a ligand-activating transcription factor that may be activated in response to infection. Its activation has been postulated many times as part of the mechanism behind the cytokine storm and poor clinical outcomes including increased fatalities associated with COVID-19 $(145,178,179,273,274)$. While cytokines protect against viral infections, they can also be aberrantly regulated and produced excessively. This may unintentionally induce indoleamine 2,3-dioxygenase (IDO), most excessively in male COVID-19 patients, leading to abnormal accumulation of kynurenine that activates the AHR. The AhR is widely expressed in various tissues and thus transcriptionally upregulates the expression of ACE2 receptor in macaques infected with SARS-CoV-2 (273). This enhances SARS-CoV-2 infection resulting in cytopathic effects in various cells and impaired antiviral response, thereby leading to systemic tissue damage and organ failure.

Furthermore, the AHR activation has also been shown to be differentially regulated in comorbidities (e.g. smoking, age, obesity, hypertension, and diabetes) that are strongly linked to poor clinical outcomes of COVID-19 (275-278). Different epigenetic regulation of AHR (181, 181, 279-282) could explain epigenetic regulation of ACE2 receptor, differentially methylated CpG sites observed in COVID-19 and poor clinical 
outcomes of COVID-19 in some individuals. For instance, activation of the AHR is also associated with reversible hypermethylation in human malignancy including acute lymphoblastic leukaemia (ALL) in in vitro studies (181). When demethylated by methylation inhibitor zebularine, AHR-related methylation inhibition restored normal cells phenotype and prevented tumorigenesis (181), suggesting it as a suitable and promising candidate/s for epigenetic therapy.

Likewise, various clinically approved drugs, such as dexamethasone, that are currently used/tested to ameliorate the COVID-19, have been shown to impact the activity of the AHR and to be involved in resistance to therapy, not only in infectious diseases (e.g. tuberculosis) but also in cancer (e.g. melanoma) (279, 280, 283-287). Curcumin and dexamethasone and are 2 classical examples of epigenetics reprogramming drugs and may be helpful to treat COVID-19 toxicity by counteracting the effects of molecules such as the AHR $(279,280)$. Of note, curcumin can modulate AHR activity $(281,288)$. Curcumin is a turmeric herb that exerts its potent anti-inflammatory and antioxidant properties by inducing epigenetic reprogramming via regulation of DNMTs, HATs, HDACs, and miRNA, reviewed in ref (282).. Various in vitro and in vivo studies in liver-related diseases have demonstrated that the use of curcumin is associated with suppressed cell growth and reduced liver injury $(289,290)$. It has been shown that curcumin exerts its activities by inhibiting HDAC activated by the nuclear factor kappa B (NF- $\mathrm{KB})$ pathway (290). It is important to note that this pathway is known to interact with AHR and thus contributing to the regulation of COVID-19mediated cytokine storm (274). Dexamethasone is a potent antioedema/fibrotic corticosteroid agent, and it was shown to accelerate AHR degradation and suppress the expression of its downstream target genes in vitro studies (291). Proper dosage of dexamethasone reduced the likelihood of progression of the disease, leading to shorter hospitalisation and reduced fatalities by approximately one third in COVID-19 patients requiring ventilation and by one fifth in those requiring oxygen (280). The use of dexamethasone in cholestatic rats was associated with decreased hepatic inflammation and oxidative stress (292). Investigating epigenetic reprogramming by various receptors and drugs may provide novel therapeutic opportunities to control the current pandemic.

\section{FUTURE PERSPECTIVES AND DIRECTIONS}

SARS-CoV-2 may trigger epigenetic alterations affecting the expression of ACE2 and various immunoregulatory genes that

\section{REFERENCES}

1. Robertson KD. Epigenetic Mechanisms of Gene Regulation. DNA Methyl Cancer Ther (2005) 13-30. doi: 10.1007/0-387-27443-X_2

2. Jones PA. Functions of DNA Methylation: Islands, Start Sites, Gene Bodies and Beyond. Nat Rev Genet (2012) 13:484-92. doi: 10.1038/nrg3230

3. Lister R, Pelizzola M, Dowen RH, Hawkins RD, Hon G, Tonti-Filippini J, et al. Human DNA Methylomes at Base Resolution Show Widespread Epigenomic Differences. Nature (2009) 462:315-22. doi: 10.1038/nature08514 play a key role in both immune defence machinery and metabolic pathways on different cells $(167,173-175)$. This may promote tissue damage and augmenting multi-organ pathology in SARSCoV-2-infected tissues. Given the evidence above, differentially methylated $\mathrm{CpG}$ sites of a wide variety of promoters encoding immunoregulatory genes and ACE2 gene may be the primary COVID-19 epigenetic signature that are set off in response to increased viral infections as part of host immune responses as commonly observed in viral infections. Differential epigenetic regulation associated with ACE2 receptor and AHR (153, 169, 217) may favour viral entry and regulation of ACE2 expression by modulating different epigenetic marks, including DNMTs, H3K27me, KDM5B and SIRT1. These epigenetic marks control metabolic and immunoregulatory pathways, thereby promoting immune evasion and cytokine storm, leading to severe clinical pathologies such as ARDS and widespread tissue damage associated with multi-organ failure $(52-61,175)$. Detection of epigenetic signatures established in COVID-19 and their dynamics during viral entry and throughout infection (e.g. from asymptomatic to mild symptomatic, severe infection and long persistent symptoms) may be valuable for timely diagnosis and to help designing therapies that may curb the severity of COVID-19 and related fatalities. Type II diabetes mellitus, hypertension and CVD are significant metabolic complications that contribute to the mortality of patients COVID-19. Discovering epigenetic markers linked to these comorbidities and how they impact the severity of COVID-19 may also be valuable for prompting treatment to prevent progression to sequelae that promote COVID-19-associated fatalities mortality.

\section{AUTHOR CONTRIBUTIONS}

MK conceived the idea and drafted the manuscript. MS, PM-A, IL, GM, TB, PK, HR, PWM, MV, JZ, and HN collected some of the literature and contributed in some sections. MS, PM-A, and SG edited and revised the manuscript. MK and PM-A made final changes, edited and finalised the manuscripts, including the figures. All authors contributed to the article and approved the submitted version.

\section{ACKNOWLEDGMENTS}

Figures were created with BioRender.com (agreement numbers: BM22S8Z265, IH22S8ZJLE, SM22S8ZAL5, AS22S8Z8HS).

4. Jones PA, Liang G. Rethinking How DNA Methylation Patterns Are Maintained. Nat Rev Genet (2009) 10:805-11. doi: 10.1038/ $\operatorname{nrg} 2651$

5. Luger K, Mäder AW, Richmond RK, Sargent DF, Richmond TJ. Crystal Structure of the Nucleosome Core Particle at $2.8 \AA$ Resolution. Nature (1997) 389:251-60. doi: 10.1038/38444

6. Jenuwein T, Laible G, Dorn R, Reuter G. SET Domain Proteins Modulate Chromatin Domains in Eu-and Heterochromatin. Cell Mol Life Sci CMLS (1998) 54:80-93. doi: 10.1007/s000180050127 
7. Kouzarides T. Chromatin Modifications and Their Function. Cell (2007) 128:693-705. doi: 10.1016/j.cell.2007.02.005

8. Martens JH, O’Sullivan RJ, Braunschweig U, Opravil S, Radolf M, Steinlein $\mathrm{P}$, et al. The Profile of Repeat-Associated Histone Lysine Methylation States in the Mouse Epigenome. EMBO J (2005) 24:800-12. doi: 10.1038/ sj.emboj.7600545

9. Liu CL, Kaplan T, Kim M, Buratowski S, Schreiber SL, Friedman N, et al. Single-Nucleosome Mapping of Histone Modifications in S. Cerevisiae. PloS Biol (2005) 3:e328. doi: 10.1371/journal.pbio.0030328

10. Lachner M, O'Carroll D, Rea S, Mechtler K, Jenuwein T. Methylation of Histone H3 Lysine 9 Creates a Binding Site for HP1 Proteins. Nature (2001) 410:116-20. doi: 10.1038/35065132

11. Steward MM, Lee J, O'Donovan A, Wyatt M, Bernstein BE, Shilatifard A. Molecular Regulation of H3K4 Trimethylation by ASH2L, a Shared Subunit of MLL Complexes. Nat Struct Mol Biol (2006) 13:852-4. doi: 10.1038/ nsmb1131

12. Huang Y, Fang J, Bedford MT, Zhang Y, Xu RM. Recognition of Histone H3 Lysine-4 Methylation by the Double Tudor Domain of JMJD2A. Science (2006) 312:748-51. doi: 10.1126/science.1125162

13. Pray-Grant MG, Daniel JA, Schieltz D, Yates JR, Grant PA. Chd1 Chromodomain Links Histone H3 Methylation With SAGA-And SLIKDependent Acetylation. Nature (2005) 433:434-8. doi: 10.1038/nature03242

14. Vakoc CR, Mandat SA, Olenchock BA, Blobel GA. Histone H3 Lysine 9 Methylation and HP1 $\gamma$ Are Associated With Transcription Elongation Through Mammalian Chromatin. Mol Cell (2005) 19:381-91. doi: 10.1016/j.molcel.2005.06.011

15. Peters AH, Mermoud JE, O'Carroll D, Pagani M, Schweizer D, Brockdorff N, et al. Histone H3 Lysine 9 Methylation Is an Epigenetic Imprint of Facultative Heterochromatin. Nat Genet (2002) 30:77-80. doi: 10.1038/ ng789

16. Piunti A, Shilatifard A. Epigenetic Balance of Gene Expression by Polycomb and COMPASS Families. Science (2016) 352:aad9780. doi: 10.1126/ science.aad 9780

17. Wu JT, Leung K, Leung GM. Nowcasting and Forecasting the Potential Domestic and International Spread of the 2019-Ncov Outbreak Originating in Wuhan, China: A Modelling Study. Lancet (2020) 395:689-97. doi: 10.1016/S0140-6736(20)30260-9

18. Hoffmann M, Kleine-Weber H, Krüger N, Mueller MA, Drosten C, Pöhlmann S. The Novel Coronavirus 2019 (2019-Ncov) Uses the SARSCoronavirus Receptor ACE2 and the Cellular Protease TMPRSS2 for Entry Into Target Cells. BioRxiv (2020) 1-23. doi: 10.1101/2020.01. 31.929042

19. Hoffmann M, Kleine-Weber H, Schroeder S, Krüger N, Herrler T, Erichsen S, et al. SARS-CoV-2 Cell Entry Depends on ACE2 and TMPRSS2 and Is Blocked by a Clinically Proven Protease Inhibitor. Cell (2020) 181:271-280. e8. doi: 10.1016/j.cell.2020.02.052

20. Lei Y, Zhang J, Schiavon CR, He M, Chen L, Shen H, et al. SARS-CoV-2 Spike Protein Impairs Endothelial Function via Downregulation of ACE 2. Circ Res (2021) 128:1323-6. doi: 10.1161/CIRCRESAHA.121.318902

21. Haga S, Yamamoto N, Nakai-Murakami C, Osawa Y, Tokunaga K, Sata T, et al. Modulation of TNF- $\alpha$-Converting Enzyme by the Spike Protein of SARS-CoV and ACE2 Induces TNF- $\alpha$ Production and Facilitates Viral Entry. Proc Natl Acad Sci (2008) 105:7809-14. doi: 10.1073/ pnas.0711241105

22. Garg M, Royce SG, Tikellis C, Shallue C, Batu D, Velkoska E, et al. Imbalance of the Renin-Angiotensin System may Contribute to Inflammation and Fibrosis in IBD: A Novel Therapeutic Target? Gut (2020) 69:841-51. doi: 10.1136/gutjnl-2019-318512

23. Gheblawi M, Wang K, Viveiros A, Nguyen Q, Zhong J, Turner AJ, et al. Angiotensin-Converting Enzyme 2: SARS-CoV-2 Receptor and Regulator of the Renin-Angiotensin System: Celebrating the 20th Anniversary of the Discovery of ACE2. Circ Res (2020) 126:1456-74. doi: 10.1161/ CIRCRESAHA. 120.317015

24. Jia H. Pulmonary Angiotensin-Converting Enzyme 2 (ACE2) and Inflammatory Lung Disease. Shock (2016) 46:239-48. doi: 10.1097/ SHK.0000000000000633

25. Garg M, Angus PW, Burrell LM, Herath C, Gibson PR, Lubel JS. The Pathophysiological Roles of the Renin-Angiotensin System in the
Gastrointestinal Tract. Aliment Pharmacol Ther (2012) 35:414-28. doi: 10.1111/j.1365-2036.2011.04971.x

26. Patel VB, Clarke N, Wang Z, Fan D, Parajuli N, Basu R, et al. Angiotensin II Induced Proteolytic Cleavage of Myocardial ACE2 Is Mediated by TACE/ ADAM-17: A Positive Feedback Mechanism in the RAS. J Mol Cell Cardiol (2014) 66:167-76. doi: 10.1016/j.yjmcc.2013.11.017

27. Zhao Y, Zhao Z, Wang Y, Zhou Y, Ma Y, Zuo W. Single-Cell RNA Expression Profiling of ACE2, the Receptor of SARS-CoV-2. Am J Respir Crit Care Med (2020) 202:756-9. doi: 10.1164/rccm.202001-0179LE

28. Gurwitz D. Angiotensin Receptor Blockers as Tentative SARS-CoV-2 Therapeutics. Drug Dev Res (2020) 81:537-40. doi: 10.1002/ddr.21656

29. Yao Y, Wang H, Liu Z. Expression of ACE2 in Airways: Implication for COVID-19 Risk and Disease Management in Patients With Chronic Inflammatory Respiratory Diseases. Clin Exp Allergy (2020) 50:1313-24. doi: 10.1111/cea.13746

30. Xie Y, Wang X, Yang P, Zhang S. COVID-19 Complicated by Acute Pulmonary Embolism. Radiol: Cardiothorac Imaging (2020) 2:e200067. doi: $10.1148 /$ ryct.2020200067

31. Yassin A, Abdelkader MA, Mohammed RM, Osman AM. CT Pulmonary Angiography in COVID-19 Pneumonia: Relationship Between Pulmonary Embolism and Disease Severity. Egypt J Radiol Nucl Med (2021) 52:1-8. doi: 10.1186/s43055-020-00389-7

32. Bonaventura A, Vecchié A, Wang TS, Lee E, Cremer PC, Carey B, et al. Targeting GM-CSF in COVID-19 Pneumonia: Rationale and Strategies. Front Immunol (2020) 11:1625. doi: 10.3389/fimmu.2020.01625

33. Huang C, Wang Y, Li X, Ren L, Zhao J, Hu Y, et al. Clinical Features of Patients Infected With 2019 Novel Coronavirus in Wuhan, China. Lancet (2020) 395:497-506. doi: 10.1016/S0140-6736(20)30183-5

34. Combes TW, Orsenigo F, Stewart A, Mendis AJR, Dunn-Walters D, Gordon $S$, et al. CSF1R Defines the Mononuclear Phagocyte System Lineage in Human Blood in Health and COVID-19. Immunother Adv (2021) 1:ltab003. doi: 10.1093/immadv/ltab003

35. Yang $\mathrm{X}, \mathrm{Yu} \mathrm{Y,} \mathrm{Xu} \mathrm{J,} \mathrm{Shu} \mathrm{H,} \mathrm{Liu} \mathrm{H,} \mathrm{Wu} \mathrm{Y,} \mathrm{et} \mathrm{al.} \mathrm{Clinical} \mathrm{Course} \mathrm{and}$ Outcomes of Critically Ill Patients With SARS-CoV-2 Pneumonia in Wuhan, China: A Single-Centered, Retrospective, Observational Study. Lancet Respir Med (2020) 8:475-81. doi: 10.1016/S2213-2600(20)30079-5

36. Danzi GB, Loffi M, Galeazzi G, Gherbesi E. Acute Pulmonary Embolism and COVID-19 Pneumonia: A Random Association? Eur Heart J (2020) 41:1858-8. doi: 10.1093/eurheartj/ehaa254

37. Poissy J, Goutay J, Caplan M, Parmentier E, Duburcq T, Lassalle F, et al. Pulmonary Embolism in Patients With COVID-19: Awareness of an Increased Prevalence. Circulation (2020) 142:184-6. doi: 10.1161/ CIRCULATIONAHA.120.047430

38. Ferreira-Gomes M, Kruglov A, Durek P, Heinrich F, Tizian C, Heinz GA, et al. SARS-CoV-2 in Severe COVID-19 Induces a TGF- $\beta$-Dominated Chronic Immune Response That Does Not Target Itself. Nat Commun (2021) 12:1-14. doi: 10.1038/s41467-021-22210-3

39. Lechowicz K, Drożdżal S, Machaj F, Rosik J, Szostak B, Zegan-Barańska M, et al. COVID-19: The Potential Treatment of Pulmonary Fibrosis Associated With SARS-CoV-2 Infection. J Clin Med (2020) 9:1917. doi: 10.3390/ jcm9061917

40. Chiu C, Ellebedy AH, Wrammert J, Ahmed R. B Cell Responses to Influenza Infection and Vaccination. Influenza Pathogenesis Control-Volume II (2014) 11:381-98. doi: 10.1007/82_2014_425

41. Zhang B, Hu Y, Chen L, Yau T, Tong Y, Hu J, et al. Mining of Epitopes on Spike Protein of SARS-CoV-2 From COVID-19 Patients. Cell Res (2020) 30:702-4. doi: 10.1038/s41422-020-0366-x

42. Pene J, Gauchat JF, Lecart S, Drouet E, Guglielmi P, Boulay V, et al. Cutting Edge: IL-21 Is a Switch Factor for the Production of IgG1 and IgG3 by Human B Cells. J Immunol (2004) 172:5154-7. doi: 10.4049/ jimmunol.172.9.5154

43. Islam KB, Nilsson L, Sideras P, Hammarström L, Smith CE. TGF- $\beta 1$ Induces Germ-Line Transcripts of Both IgA Subclasses in Human B Lymphocytes. Int Immunol (1991) 3:1099-106. doi: 10.1093/intimm/3.11.1099

44. Chen C, Zhang XR, Ju ZY, He WF. Advances in the Research of Mechanism and Related Immunotherapy on the Cytokine Storm Induced by Coronavirus Disease 2019. Zhonghua Shao Shang Za Zhi (2020) 36:471-5. doi: 10.3760/cma.j.cn501120-20200224-00088 
45. Tanaka T, Narazaki M, Kishimoto T. Immunotherapeutic Implications of IL-6 Blockade for Cytokine Storm. Immunotherapy (2016) 8:959-70. doi: 10.2217/imt-2016-0020

46. Pathan N, Hemingway CA, Alizadeh AA, Stephens AC, Boldrick JC, Oragui EE, et al. Role of Interleukin 6 in Myocardial Dysfunction of Meningococcal Septic Shock. Lancet (2004) 363:203-9. doi: 10.1016/S0140-6736(03)15326-3

47. Clerkin KJ, Fried JA, Raikhelkar J, Sayer G, Griffin JM, Masoumi A, et al. COVID-19 and Cardiovascular Disease. Circulation (2020) 141:1648-55. doi: 10.1161/CIRCULATIONAHA.120.046941

48. Kang Y, Chen T, Mui D, Ferrari V, Jagasia D, Scherrer-Crosbie M, et al. Cardiovascular Manifestations and Treatment Considerations in COVID19. Heart (2020) 106:1132-41. doi: 10.1136/heartjnl-2020-317056

49. Ediz C, Tavukcu HH, Akan S, Kizilkan YE, Alcin A, Oz K, et al. Is There Any Association of COVID-19 With Testicular Pain and Epididymo-Orchitis? Int J Clin Pract (2021) 75:e13753. doi: 10.1111/ijcp.13753

50. Xiao F, Tang M, Zheng X, Liu Y, Li X, Shan H. Evidence for Gastrointestinal Infection of SARS-CoV-2. Gastroenterology (2020) 158:1831-3.e3. doi: 10.1053/j.gastro.2020.02.055

51. Carvelli J, Demaria O, Vély F, Batista L, Benmansour NC, Fares J, et al. Association of COVID-19 Inflammation With Activation of the C5a-C5aR1 Axis. Nature (2020) 588:146-50. doi: 10.1038/s41586-020-2600-6

52. Zhang H, Kang Z, Gong H, Xu D, Wang J, Li Z, et al. The Digestive System Is a Potential Route of 2019-Ncov Infection: A Bioinformatics Analysis Based on Single-Cell Transcriptomes. BioRxiv (2020) 1-26. doi: 10.1101/ 2020.01.30.927806

53. Wu C, Zheng S, Chen Y, Zheng M. Single-Cell RNA Expression Profiling of ACE2, the Putative Receptor of Wuhan 2019-Ncov, in the Nasal Tissue. MedRxiv (2020) 1-13. doi: 10.1101/2020.02.11.20022228

54. Qi F, Qian S, Zhang S, Zhang Z. Single Cell RNA Sequencing of 13 Human Tissues Identify Cell Types and Receptors of Human Coronaviruses. Biochem Biophys Res Commun (2020) 526:135-40. doi: 10.1016/ j.bbrc.2020.03.044

55. Chai X, Hu L, Zhang Y, Han W, Lu Z, Ke A, et al. Specific ACE2 Expression in Cholangiocytes may Cause Liver Damage After 2019-Ncov Infection. biorxiv (2020) 1-13. doi: 10.1101/2020.02.03.931766

56. Ni W, Yang X, Yang D, Bao J, Li R, Xiao Y, et al. Role of AngiotensinConverting Enzyme 2 (ACE2) in COVID-19. Crit Care (2020) 24:1-10. doi: 10.1186/s13054-020-03120-0

57. Gu J, Korteweg C. Pathology and Pathogenesis of Severe Acute Respiratory Syndrome. Am J Pathol (2007) 170:1136-47. doi: 10.2353/ ajpath.2007.061088

58. Gu J, Gong E, Zhang B, Zheng J, Gao Z, Zhong Y, et al. Multiple Organ Infection and the Pathogenesis of SARS. J Exp Med (2005) 202:415-24. doi: 10.1084/jem.20050828

59. Danilczyk U, Sarao R, Remy C, Benabbas C, Stange G, Richter A, et al. Essential Role for Collectrin in Renal Amino Acid Transport. Nature (2006) 444:1088-91. doi: 10.1038/nature05475

60. Hamming I, Timens W, Bulthuis M, Lely A, Navis GV, van Goor H. Tissue Distribution of ACE2 Protein, the Functional Receptor for SARS Coronavirus. A First Step in Understanding SARS Pathogenesis. J Pathol: A J Pathol Soc Great Britain Ireland (2004) 203:631-7. doi: 10.1002/ path. 1570

61. Meinhardt J, Radke J, Dittmayer C, Franz J, Thomas C, Mothes R, et al. Olfactory Transmucosal SARS-CoV-2 Invasion as a Port of Central Nervous System Entry in Individuals With COVID-19. Nat Neurosci (2020) 24:16775. doi: 10.1038/s41593-020-00758-5

62. Sungnak W, Huang N, Bécavin C, Berg M, Queen R, Litvinukova M, et al. SARS-CoV-2 Entry Factors Are Highly Expressed in Nasal Epithelial Cells Together With Innate Immune Genes. Nat Med (2020) 26:681-7. doi: 10.1038/s41591-020-0868-6

63. Butowt R, von Bartheld CS. Anosmia in COVID-19: Underlying Mechanisms and Assessment of an Olfactory Route to Brain Infection. Neuroscientist (2020) 1-22. doi: 10.1177/1073858420956905

64. Lechien JR, Chiesa-Estomba CM, De Siati DR, Horoi M, Le Bon SD, Rodriguez A, et al. Olfactory and Gustatory Dysfunctions as a Clinical Presentation of Mild-to-Moderate Forms of the Coronavirus Disease (COVID-19): A Multicenter European Study. Eur Arch Oto-RhinoLaryngol (2020) 277:2251-61. doi: 10.1007/s00405-020-05965-1
65. Paniz-Mondolfi A, Bryce C, Grimes Z, Gordon RE, Reidy J, Lednicky J, et al. Central Nervous System Involvement by Severe Acute Respiratory Syndrome Coronavirus-2 (SARS-CoV-2). J Med Virol (2020) 92:699-702. doi: $10.1002 /$ jmv. 25915

66. von Weyhern CH, Kaufmann I, Neff F, Kremer M. Early Evidence of Pronounced Brain Involvement in Fatal COVID-19 Outcomes. Lancet (2020) 395:e109.

67. Mao L, Wang M, Chen S, He Q, Chang J, Hong C, et al. Neurological Manifestations of Hospitalized Patients With COVID-19 in Wuhan, China: A Retrospective Case Series Study. MedRxiv (2020) 1-26. doi: 10.2139/ ssrn. 3544840

68. Guo Y, Cao Q, Hong Z, Tan Y, Chen S, Jin H, et al. The Origin, Transmission and Clinical Therapies on Coronavirus Disease 2019 (COVID-19) Outbreak-an Update on the Status. Military Med Res (2020) 7:1-10. doi: 10.1186/s40779-020-00240-0

69. Xu Z, Shi L, Wang Y, Zhang J, Huang L, Zhang C, et al. Pathological Findings of COVID-19 Associated With Acute Respiratory Distress Syndrome. Lancet Respir Med (2020) 8:420-2. doi: 10.1016/S2213-2600

70. Solomon IH, Normandin E, Bhattacharyya S, Mukerji SS, Keller K, Ali AS, et al. Neuropathological Features of Covid-19. N Engl J Med (2020) 383:98992. doi: 10.1056/NEJMc2019373

71. Giorgianni A, Vinacci G, Agosti E, Mercuri A, Baruzzi F. Neuroradiological Features in COVID-19 Patients: First Evidence in a Complex Scenario. J Neuroradiol (2020) 47:474-6. doi: 10.1016/j.neurad.2020.05.005

72. Silva RAP, Chu Y, Miller JD, Mitchell IJ, Penninger JM, Faraci FM, et al. Impact of ACE2 Deficiency and Oxidative Stress on Cerebrovascular Function With Aging. Stroke (2012) 43:3358-63. doi: 10.1161/ STROKEAHA.112.667063

73. Feterik K, Smith L, Katusic ZS. Angiotensin-(1-7) Causes EndotheliumDependent Relaxation in Canine Middle Cerebral Artery. Brain Res (2000) 873:75-82. doi: 10.1016/S0006-8993(00)02482-3

74. Monteil V, Kwon H, Prado P, Hagelkrüys A, Wimmer RA, Stahl M, et al. Inhibition of SARS-CoV-2 Infections in Engineered Human Tissues Using Clinical-Grade Soluble Human ACE2. Cell (2020) 181:905-13. doi: 10.1016/ j.cell.2020.04.004

75. Varga Z, Flam AJ, Steiger P, Haberecker M, Andermatt R, Zinkernagel AS, et al. Endothelial Cell Infection and Endotheliitis in COVID-19. Lancet (2020) 395:1417-8. doi: 10.1016/S0140-6736(20)30937-5

76. Chen L, Li X, Chen M, Feng Y, Xiong C. The ACE2 Expression in Human Heart Indicates New Potential Mechanism of Heart Injury Among Patients Infected With SARS-CoV-2. Cardiovasc Res (2020) 116:1097-100. doi: $10.1093 / \mathrm{cvr} / \mathrm{cvaa} 078$

77. Durand MJ, Zinkevich NS, Riedel M, Gutterman DD, Nasci VL, Salato VK, et al. Vascular Actions of Angiotensin 1-7 in the Human Microcirculation: Novel Role for Telomerase. Arterioscler Thromb Vasc Biol (2016) 36:125462. doi: 10.1161/ATVBAHA.116.307518

78. Fang C, Stavrou E, Schmaier AA, Grobe N, Morris M, Chen A, et al. Angiotensin 1-7 and Mas Decrease Thrombosis in Bdkrb2-/- Mice by Increasing NO and Prostacyclin to Reduce Platelet Spreading and Glycoprotein VI Activation. Blood J Am Soc Hematol (2013) 121:3023-32. doi: 10.1182/blood-2012-09-459156

79. Teuwen L, Geldhof V, Pasut A, Carmeliet P. COVID-19: The Vasculature Unleashed. Nat Rev Immunol (2020) 20:389-91. doi: 10.1038/s41577-0200343-0

80. Wang Y, Liu S, Liu H, Li W, Lin F, Jiang L, et al. SARS-CoV-2 Infection of the Liver Directly Contributes to Hepatic Impairment in Patients With COVID-19. J Hepatol (2020) 73:807-16. doi: 10.1016/j.jhep.2020.05.002

81. Lei F, Liu Y, Zhou F, Qin J, Zhang P, Zhu L, et al. Longitudinal Association Between Markers of Liver Injury and Mortality in COVID-19 in China. Hepatology (2020) 72:389-98. doi: 10.1002/hep.31301

82. de la Rica R, Borges M, Aranda M, Del Castillo A, Socias A, Payeras A, et al. Low Albumin Levels Are Associated With Poorer Outcomes in a Case Series of COVID-19 Patients in Spain: A Retrospective Cohort Study. Microorganisms (2020) 8:1106. doi: 10.3390/microorganisms8081106

83. Chen N, Zhou M, Dong X, Qu J, Gong F, Han Y, et al. Epidemiological and Clinical Characteristics of 99 Cases of 2019 Novel Coronavirus Pneumonia in Wuhan, China: A Descriptive Study. Lancet (2020) 395:507-13. doi: 10.1016/S0140-6736(20)30211-7 
84. Bangash MN, Patel J, Parekh D. COVID-19 and the Liver: Little Cause for Concern. Lancet Gastroenterol Hepatol (2020) 5:529-30. doi: 10.1016/S24681253(20)30084-4

85. Schmulson M, Dávalos M, Berumen J. Beware: Gastrointestinal Symptoms can be a Manifestation of COVID-19. Rev Gastroenterología México (English Edition) (2020) 85:282-7. doi: 10.1016/j.rgmxen.2020.04.001

86. Zhong P, Xu J, Yang D, Shen Y, Wang L, Feng Y, et al. COVID-19Associated Gastrointestinal and Liver Injury: Clinical Features and Potential Mechanisms. Signal Transduction Targeted Ther (2020) 5:1-8. doi: 10.1038/ s41392-020-00373-7

87. Lu C, Hou N. Skin Hyperpigmentation in COVID-19 Patients: Is Polymyxin B the Culprit? Front Pharmacol (2020) 11:1304. doi: 10.3389/fphar.2020.01304

88. Liu X, Xue R, Yang C, Gu J, Chen S, Zhang S. Cholestasis-Induced Bile Acid Elevates Estrogen Level via Farnesoid X Receptor-Mediated Suppression of the Estrogen Sulfotransferase SULT1E1. J Biol Chem (2018) 293:12759-69. doi: $10.1074 /$ jbc.RA118.001789

89. Jee S, Lee S, Chiu H, Chang C, Chen TJ. Effects of Estrogen and Estrogen Receptor in Normal Human Melanocytes. Biochem Biophys Res Commun (1994) 199:1407-12. doi: 10.1006/bbrc.1994.1387

90. Burra P. Liver Abnormalities and Endocrine Diseases. Best Pract Res Clin Gastroenterol (2013) 27:553-63. doi: 10.1016/j.bpg.2013.06.014

91. Videira ,InêsFd, Moura DFL, Magina S. Mechanisms Regulating Melanogenesis. Bras Dermatol (2013) 88:76-83. doi: 10.1590/S036505962013000100009

92. Zhao B, Ni C, Gao R, Wang Y, Yang L, Wei J, et al. Recapitulation of SARSCoV-2 Infection and Cholangiocyte Damage With Human Liver Ductal Organoids. Protein Cell (2020) 11:771-5. doi: 10.1007/s13238-020-00718-6

93. Yang XH, Li RR, Sun RH, Liu J, Chen DC. Focus on Coronavirus Disease 2019 Associated Coagulopathy. Chin (Engl) (2020) 133:2239-41. doi: 10.1097/CM9.0000000000001019

94. Zhang S, Liu Y, Wang X, Yang L, Li H, Wang Y, et al. SARS-CoV-2 Binds Platelet ACE2 to Enhance Thrombosis in COVID-19. J Hematol Oncol (2020) 13:1-22. doi: 10.1186/s13045-020-00954-7

95. Hottz ED, Azevedo-Quintanilha IG, Palhinha L, Teixeira L, Barreto EA, Pão CR, et al. Platelet Activation and Platelet-Monocyte Aggregate Formation Trigger Tissue Factor Expression in Patients With Severe COVID-19. Blood J Am Soc Hematol (2020) 136:1330-41. doi: 10.1182/ blood.2020007252

96. Grover SP, Mackman N. Tissue Factor: An Essential Mediator of Hemostasis and Trigger of Thrombosis. Arterioscler Thromb Vasc Biol (2018) 38:709-25. doi: 10.1161/ATVBAHA.117.309846

97. Gholizadeh P, Safari R, Marofi P, Zeinalzadeh E, Pagliano P, Ganbarov K, et al. Alteration of Liver Biomarkers in Patients With SARS-CoV-2 (COVID-19). J Inflammation Res (2020) 13:285-92. doi: 10.2147/JIR.S257078

98. Cai Q, Huang D, Yu H, Zhu Z, Xia Z, Su Y, et al. COVID-19: Abnormal Liver Function Tests. J Hepatol (2020) 73:566-74. doi: 10.1016/j.jhep.2020.04.006

99. Fan Z, Chen L, Li J, Cheng X, Yang J, Tian C, et al. Clinical Features of COVID-19-Related Liver Functional Abnormality. Clin Gastroenterol Hepatol (2020) 18:1561-6. doi: 10.1016/j.cgh.2020.04.002

100. Garg M, Christensen B, Lubel JS. Gastrointestinal ACE2, COVID-19 and IBD: Opportunity in the Face of Tragedy? Gastroenterology (2020) 159:16231624.e3. doi: 10.1053/j.gastro.2020.04.051

101. Guo M, Tao W, Flavell RA, Zhu S. Potential Intestinal Infection and FaecalOral Transmission of SARS-CoV-2. Nat Rev Gastroenterol Hepatol (2021) 18:269-83. doi: 10.1038/s41575-021-00416-6

102. Zheng S, Fan J, Yu F, Feng B, Lou B, Zou Q, et al. Viral Load Dynamics and Disease Severity in Patients Infected With SARS-CoV-2 in Zhejiang Province, China, January-March 2020: Retrospective Cohort Study. BMJ (2020) 369:m1443. doi: 10.1136/bmj.m1443

103. Parasa S, Desai M, Chandrasekar VT, Patel HK, Kennedy KF, Roesch T, et al. Prevalence of Gastrointestinal Symptoms and Fecal Viral Shedding in Patients With Coronavirus Disease 2019: A Systematic Review and MetaAnalysis. JAMA network Open (2020) 3:e2011335-e2011335. doi: 10.1001/ jamanetworkopen.2020.11335

104. Wölfel R, Corman VM, Guggemos W, Seilmaier M, Zange S, Müller MA, et al. Virological Assessment of Hospitalized Patients With COVID-2019. Nature (2020) 581:465-9. doi: 10.1038/s41586-020-2196-x
105. Effenberger M, Grabherr F, Mayr L, Schwaerzler J, Nairz M, Seifert M, et al. Faecal Calprotectin Indicates Intestinal Inflammation in COVID-19. Gut (2020) 69:1543-4. doi: 10.1136/gutjnl-2020-321388

106. Baughn LB, Sharma N, Elhaik E, Sekulic A, Bryce AH, Fonseca R. Targeting TMPRSS2 in SARS-CoV-2 Infection. In: Anonymous Mayo Clinic Proceedings. Elsevier (2020) 95:1989-1999.

107. Chen L, Huang X, Yi Z, Deng Q, Jiang N, Feng C, et al. Ultrasound Imaging Findings of Acute Testicular Infection in Patients With Coronavirus Disease 2019: A Single-Center-Based Study in Wuhan, China. J Ultrasound Med (2020) 40:1787-94. doi: 10.1002/jum.15558

108. Ma X, Guan C, Chen R, Wang Y, Feng S, Wang R, et al. Pathological and Molecular Examinations of Postmortem Testis Biopsies Reveal SARS-CoV-2 Infection in the Testis and Spermatogenesis Damage in COVID-19 Patients. Cell Mol Immunol (2021) 18:487-9. doi: 10.1038/s41423-020-00604-5

109. Bendayan M, Boitrelle F. Covid-19 and Impairment of Spermatogenesis: What If Fever was the Only Cause? EClinicalMedicine (2020) 29:29-30. doi: 10.1016/j.eclinm.2020.100604

110. Gagliardi L, Bertacca C, Centenari C, Merusi I, Parolo E, Ragazzo V, et al. Orchiepididymitis in a Boy With COVID-19. Pediatr Infect Dis J (2020) 39: e200-2. doi: 10.1097/INF.0000000000002769 [doi

111. La Marca A, Busani S, Donno V, Guaraldi G, Ligabue G, Girardis M. Testicular Pain as an Unusual Presentation of COVID-19: A Brief Review of SARS-CoV-2 and the Testis. Reprod biomed Online (2020) 41:903-6. doi: 10.1016/j.rbmo.2020.07.017

112. Carneiro F, Teixeira TA, Bernardes FS, Pereira MS, Milani G, Duarte-Neto AN, et al. Radiological Patterns of Incidental Epididymitis in Mild-toModerate COVID-19 Patients Revealed by Colour Doppler Ultrasound. Andrologia (2021) 53:e13973. doi: 10.1111/and.13973

113. Bridwell RE, Merrill DR, Griffith SA, Wray J, Oliver JJ. A Coronavirus Disease 2019 (COVID-19) Patient With Bilateral Orchitis. Am J Emerg Med (2021) 42:260.e3-5. doi: 10.1016/j.ajem.2020.08.068

114. Wu FC, Tajar A, Pye SR, Silman AJ, Finn JD, O’Neill TW, et al. Hypothalamic-Pituitary-Testicular Axis Disruptions in Older Men Are Differentially Linked to Age and Modifiable Risk Factors: The European Male Aging Study. J Clin Endocrinol Metab (2008) 93:2737-45. doi: 10.1210/ jc.2007-1972

115. Çayan S, Uğuz M, Saylam B, Akbay E. Effect of Serum Total Testosterone and Its Relationship With Other Laboratory Parameters on the Prognosis of Coronavirus Disease 2019 (COVID-19) in SARS-CoV-2 Infected Male Patients: A Cohort Study. Aging Male (2020) 23:1493-503. doi: 10.1080/ 13685538.2020.1807930

116. Ma L, Xie W, Li D, Shi L, Ye G, Mao Y, et al. Evaluation of Sex-Related Hormones and Semen Characteristics in Reproductive-Aged Male COVID19 Patients. J Med Virol (2021) 93:456-62. doi: 10.1002/jmv.26259

117. Vishvkarma R, Rajender S. Could SARS-CoV-2 Affect Male Fertility? Andrologia (2020) 52:e13712. doi: 10.1111/and.13712

118. Yang M, Chen S, Huang B, Zhong J, Su H, Chen Y, et al. Pathological Findings in the Testes of COVID-19 Patients: Clinical Implications. Eur Urol Focus (2020) 6:1124-9. doi: 10.1016/j.euf.2020.05.009

119. Mannur S, Jabeen T, Khader MA, Rao LSS. Post-Covid-19 Associated Decline in Long-Term Male Fertility and Embryo Quality During Assisted Reproductive Technology. QJM (2021) 1-3. doi: 10.1093/qjmed/hcab019

120. Karlberg J, Chong D, Lai W. Do Men Have a Higher Case Fatality Rate of Severe Acute Respiratory Syndrome Than Women Do? Am J Epidemiol (2004) 159:229-31. doi: 10.1093/aje/kwh056

121. Sheu CC, Zhai R, Su L, Tejera P, Gong MN, Thompson BT, et al. Sex-Specific Association of Epidermal Growth Factor Gene Polymorphisms With Acute Respiratory Distress Syndrome. Eur Respir J (2009) 33:543-50. doi: 10.1183/ 09031936.00091308

122. Rathod KS, Kapil V, Velmurugan S, Khambata RS, Siddique U, Khan S, et al. Accelerated Resolution of Inflammation Underlies Sex Differences in Inflammatory Responses in Humans. J Clin Invest (2017) 127:169-82. doi: $10.1172 /$ JCI89429

123. Peckham H, de Gruijter NM, Raine C, Radziszewska A, Ciurtin C, Wedderburn LR, et al. Male Sex Identified by Global COVID-19 MetaAnalysis as a Risk Factor for Death and ITU Admission. Nat Commun (2020) 11:1-10. doi: 10.1038/s41467-020-19741-6 
124. Dehingia N, Raj A. Sex Differences in COVID-19 Case Fatality: Do We Know Enough? Lancet Glob Health (2021) 9:e14-5. doi: 10.1016/S2214-109X(20) 30464-2

125. Gendrel A, Apedaile A, Coker H, Termanis A, Zvetkova I, Godwin J, et al. Smchd1-Dependent and-Independent Pathways Determine Developmental Dynamics of CpG Island Methylation on the Inactive X Chromosome. Dev Cell (2012) 23:265-79. doi: 10.1016/j.devcel.2012.06.011

126. Harper PS. Mary Lyon and the Hypothesis of Random X Chromosome Inactivation. Hum Genet (2011) 130:169-74. doi: 10.1007/s00439-0111013-x

127. Brockdorff N, Ashworth A, Kay GF, McCabe VM, Norris DP, Cooper PJ, et al. The Product of the Mouse Xist Gene Is a $15 \mathrm{~Kb}$ Inactive X-Specific Transcript Containing No Conserved ORF and Located in the Nucleus. Cell (1992) 71:515-26. doi: 10.1016/0092-8674(92)90519-I

128. Penny GD, Kay GF, Sheardown SA, Rastan S, Brockdorff N. Requirement for Xist in X Chromosome Inactivation. Nature (1996) 379:131-7. doi: 10.1038/ 379131a0

129. Maclary E, Hinten M, Harris C, Sethuraman S, Gayen S, Kalantry S. PRC2 Represses Transcribed Genes on the Imprinted Inactive X Chromosome in Mice. Genome Biol (2017) 18:1-17. doi: 10.1186/s13059-017-1211-5

130. Żylicz JJ, Bousard A, Žumer K, Dossin F, Mohammad E, da Rocha ST, et al. The Implication of Early Chromatin Changes in X Chromosome Inactivation. Cell (2019) 176:182-97.e23. doi: 10.1016/j.cell.2018.11.041

131. Souyris M, Cenac C, Azar P, Daviaud D, Canivet A, Grunenwald S, et al. TLR7 Escapes X Chromosome Inactivation in Immune Cells. Sci Immunol (2018) 3(19):eaap8855. doi: 10.1126/sciimmunol.aap8855

132. Takahashi T, Iwasaki A. Sex Differences in Immune Responses. Science (2021) 371:347-8. doi: 10.1126/science.abe7199

133. Berletch JB, Yang F, Xu J, Carrel L, Disteche CM. Genes That Escape From X Inactivation. Hum Genet (2011) 130:237-45. doi: 10.1007/s00439-011-1011-z

134. Balaton BP, Cotton AM, Brown CJ. Derivation of Consensus Inactivation Status for X-Linked Genes From Genome-Wide Studies. Biol sex Dif (2015) 6:1-11. doi: 10.1186/s13293-015-0053-7

135. Garg S, Kim L, Whitaker M, O’Halloran A, Cummings C, Holstein R, et al. Hospitalization Rates and Characteristics of Patients Hospitalized With Laboratory-Confirmed Coronavirus Disease 2019 - COVID-NET, 14 States, March 1-30, 2020. MMWR Morb Mortal Wkly Rep (2020) 69:45864. doi: $10.15585 / \mathrm{mmwr} . \mathrm{mm} 6915 \mathrm{e} 3$

136. Guan WJ, Liang WH, Zhao Y, Liang HR, Chen ZS, Li YM, et al. Comorbidity and Its Impact on 1590 Patients With COVID-19 in China: A Nationwide Analysis. Eur Respir J (2020) 55:1-7. doi: 10.1183/ 13993003.00547-2020

137. Vardavas CI. COVID-19 and Smoking: A Systematic Review of the Evidence. Tob Induc Dis (2020) 18:20. doi: 10.18332/tid/119324

138. Cai H. Sex Difference and Smoking Predisposition in Patients With COVID19. Lancet Respir Med (2020) 8:e20-2600(20)30117-X. doi: 10.1016/S22132600(20)30117-X

139. Cai Y, Kim DJ, Takahashi T, Broadhurst DI, Ma S, Rattray NJW, et al. Kynurenic Acid Underlies Sex-Specific Immune Responses to COVID-19. medRxiv(2020) 1-26. doi: 10.1101/2020.09.06.20189159

140. Chakravarty D, Nair SS, Hammouda N, Ratnani P, Gharib Y, Wagaskar V, et al. Sex Differences in SARS-CoV-2 Infection Rates and the Potential Link to Prostate Cancer. Commun Biol (2020) 3:1-12. doi: 10.1038/s42003-0201088-9

141. Sama IE, Ravera A, Santema BT, Van Goor H, Ter Maaten JM, Cleland JG, et al. Circulating Plasma Concentrations of Angiotensin-Converting Enzyme 2 in Men and Women With Heart Failure and Effects of Renin-AngiotensinAldosterone Inhibitors. Eur Heart J (2020) 41:1810-7. doi: 10.1093/ eurheartj/ehaa373

142. Emilsson V, Gudmundsson EF, Aspelund T, Jonsson BG, Gudjonsson A, Launer LJ, et al. ACE2 Levels Are Altered in Comorbidities Linked to Severe Outcome in COVID-19. MedRxiv (2020) 1-14. doi: 10.1101/ 2020.06.04.20122044

143. Han L, Zhuang M, Zheng Y, Zhang J, Nan M, Wang P, et al. SARS-CoV-2 ORF9b Antagonizes Type I and III Interferons by Targeting Multiple Components of RIG-I/MDA-5-MAVS, TLR3-TRIF, and cGAS-STING Signaling Pathways. bioRxiv (2020) 93:5376-89. doi: 10.1101/ 2020.08.16.252973
144. Ruan Q, Yang K, Wang W, Jiang L, Song J. Clinical Predictors of Mortality Due to COVID-19 Based on an Analysis of Data of 150 Patients From Wuhan, China. Intensive Care Med (2020) 46:846-8. doi: 10.1007/s00134020-05991-x

145. Dai W, Cao D, Zhang W, Wei Y, Ding D, Li B, et al. Integrated Bioinformatics Analysis Reveals Key Candidate Genes and Cytokine Pathways Involved in COVID-19 After Rhinovirus Infection in Asthma Patients. Med Sci Monit (2020) 26:e928861. doi: 10.12659/MSM.928861

146. Yang L, Kirby JE, Sunwoo H, Lee JT. Female Mice Lacking Xist RNA Show Partial Dosage Compensation and Survive to Term. Genes Dev (2016) 30:1747-60. doi: 10.1101/gad.281162.116[doi

147. Marahrens Y, Panning B, Dausman J, Strauss W, Jaenisch R. Xist-Deficient Mice Are Defective in Dosage Compensation But Not Spermatogenesis. Genes Dev (1997) 11:156-66. doi: 10.1101/gad.11.2.156[doi

148. Mudersbach T, Siuda D, Kohlstedt K, Fleming I. Epigenetic Control of the Angiotensin-Converting Enzyme in Endothelial Cells During Inflammation. PloS One (2019) 14:e0216218. doi: 10.1371/journal.pone.0216218

149. Sharma K, Morla S, Goyal A, Kumar S. Computational Guided Drug Repurposing for Targeting 2'-O-Ribose Methyltransferase of SARS-CoV-2. Life Sci (2020) 259:118169. doi: 10.1016/j.lfs.2020.118169

150. Decroly E, Debarnot C, Ferron F, Bouvet M, Coutard B, Imbert I, et al. Crystal Structure and Functional Analysis of the SARS-Coronavirus RNA Cap 2'-O-Methyltransferase Nsp10/Nsp16 Complex. PloS Pathog (2011) 7: e1002059. doi: 10.1371/journal.ppat.1002059

151. Rosas-Lemus M, Minasov G, Shuvalova L, Inniss NL, Kiryukhina O, Brunzelle J, et al. High-Resolution Structures of the SARS-CoV-2 2'-OMethyltransferase Reveal Strategies for Structure-Based Inhibitor Design. Sci Signal (2020) 13:1-24. doi: 10.1126/scisignal.abe1202

152. Paramasivam A. RNA 2'-O-Methylation Modification and Its Implication in COVID-19 Immunity. Cell Death Discov (2020) 6:1-3. doi: 10.1038/s41420020-00358-Z

153. Li S, Ma F, Yokota T, Garcia G, Palermo A, Wang Y, et al. Metabolic Reprogramming and Epigenetic Changes of Vital Organs in SARS-CoV-2Induced Systemic Toxicity. JCI Insight (2021) 6:1-18. doi: 10.1172/ jci.insight. 145027

154. Zhu H, Wang G, Qian J. Transcription Factors as Readers and Effectors of DNA Methylation. Nat Rev Genet (2016) 17:551. doi: 10.1038/nrg.2016.83

155. Okano M, Bell DW, Haber DA, Li E. DNA Methyltransferases Dnmt3a and Dnmt3b Are Essential for De Novo Methylation and Mammalian Development. Cell (1999) 99:247-57. doi: 10.1016/S0092-8674(00)81656-6

156. Gowher H, Jeltsch A. Enzymatic Properties of Recombinant Dnmt3a DNA Methyltransferase From Mouse: The Enzyme Modifies DNA in a NonProcessive Manner and Also Methylates Non-CpA Sites. J Mol Biol (2001) 309:1201-8. doi: 10.1006/jmbi.2001.4710

157. Guo JU, Su Y, Shin JH, Shin J, Li H, Xie B, et al. Distribution, Recognition and Regulation of Non-CpG Methylation in the Adult Mammalian Brain. Nat Neurosci (2014) 17:215-22. doi: 10.1038/nn.3607

158. He Y, Ecker JR. Non-CG Methylation in the Human Genome. Annu Rev Genomics Hum Genet (2015) 16:55-77. doi: 10.1146/annurev-genom090413-025437

159. Gao L, Emperle M, Guo Y, Grimm SA, Ren W, Adam S, et al. Comprehensive Structure-Function Characterization of DNMT3B and DNMT3A Reveals Distinctive De Novo DNA Methylation Mechanisms. Nat Commun (2020) 11:1-14. doi: 10.1038/s41467-020-17109-4

160. Hata K, Okano M, Lei H, Li E. Dnmt3L Cooperates With the Dnmt3 Family of De Novo DNA Methyltransferases to Establish Maternal Imprints in Mice. Development (2002) 129:1983-93. doi: 10.1242/dev.129.8.1983

161. Chedin F, Lieber MR, Hsieh CL. The DNA Methyltransferase-Like Protein DNMT3L Stimulates De Novo Methylation by Dnmt3a. Proc Natl Acad Sci USA (2002) 99:16916-21. doi: 10.1073/pnas.262443999

162. Atlasi Y, Stunnenberg HG. The Interplay of Epigenetic Marks During Stem Cell Differentiation and Development. Nat Rev Genet (2017) 18:643. doi: 10.1038/nrg.2017.57

163. Kgatle MM, Setshedi M, Hairwadzi HN. Hepatoepigenetic Alterations in Viral and Nonviral-Induced Hepatocellular Carcinoma. BioMed Res Int (2016) 2016:1-13. doi: 10.1155/2016/3956485

164. Kgatle MM, Spearman CW, Kalla AA, Hairwadzi HN. DNA Oncogenic Virus-Induced Oxidative Stress, Genomic Damage, and Aberrant Epigenetic 
Alterations. Oxid Med Cell Longevity (2017) 2017:1-16. doi: 10.1155/2017/ 3179421

165. Menachery VD, Schäfer A, Burnum-Johnson KE, Mitchell HD, Eisfeld AJ, Walters KB, et al. MERS-CoV and H5N1 Influenza Virus Antagonize Antigen Presentation by Altering the Epigenetic Landscape. Proc Natl Acad Sci (2018) 115:E1012-21. doi: 10.1073/pnas.1706928115

166. Steimle V, Otten LA, Zufferey M, Mach B. Complementation Cloning of an MHC Class II Transactivator Mutated in Hereditary MHC Class II Deficiency (or Bare Lymphocyte Syndrome). Cell (1993) 75:135-46. doi: 10.1016/S0092-8674(05)80090-X

167. Sawalha AH, Zhao M, Coit P, Lu Q. Epigenetic Dysregulation of ACE2 and Interferon-Regulated Genes Might Suggest Increased COVID-19 Susceptibility and Severity in Lupus Patients. Clin Immunol (2020) 215:108410. doi: 10.1016/j.clim.2020.108410

168. Turunen MP, Lehtola T, Heinonen SE, Assefa GS, Korpisalo P, Girnary R, et al. Efficient Regulation of VEGF Expression by Promoter-Targeted Lentiviral shRNAs Based on Epigenetic Mechanism: A Novel Example of Epigenetherapy. Circ Res (2009) 105:604-9. doi: 10.1161/CIRCRESAHA.109.200774

169. Ono R, Nakamura K, Inoue K, Naruse M, Usami T, Wakisaka-Saito N, et al. Deletion of Peg10, an Imprinted Gene Acquired From a Retrotransposon, Causes Early Embryonic Lethality. Nat Genet (2006) 38:101-6. doi: 10.1038/ ng1699

170. Akamatsu S, Wyatt AW, Lin D, Lysakowski S, Zhang F, Kim S, et al. The Placental Gene PEG10 Promotes Progression of Neuroendocrine Prostate Cancer. Cell Rep (2015) 12:922-36. doi: 10.1016/j.celrep.2015.07.012

171. Shimada K, Matsushita Y, Wakabayashi K, Takahashi M, Matsubara A, Iijima $\mathrm{Y}$, et al. Cloning and Functional Expression of Human EndothelinConverting Enzyme cDNA. Biochem Biophys Res Commun (1995) 207:80712. doi: $10.1006 /$ bbrc. 1995.1258

172. Yanagisawa H, Yanagisawa M, Kapur RP, Richardson JA, Williams SC, Clouthier DE, et al. Dual Genetic Pathways of Endothelin-Mediated Intercellular Signaling Revealed by Targeted Disruption of Endothelin Converting Enzyme-1 Gene. Development (1998) 125:825-36. doi: 10.1242/dev.125.5.825

173. Balnis J, Madrid A, Hogan KJ, Drake LA, Chieng HC, Tiwari A, et al. Blood DNA Methylation and COVID-19 Outcomes. Clin Epigenet (2021) 13:1-16. doi: 10.1186/s13148-021-01102-9

174. Menachery VD, Eisfeld AJ, Schäfer A, Josset L, Sims AC, Proll S, et al. Pathogenic Influenza Viruses and Coronaviruses Utilize Similar and Contrasting Approaches to Control Interferon-Stimulated Gene Responses. MBio (2014) 5:e01174-14. doi: 10.1128/mBio.01174-14

175. de Moura MC, Davalos V, Planas-Serra L, Alvarez-Errico D, Arribas C, Ruiz $\mathrm{M}$, et al. Epigenome-Wide Association Study of COVID-19 Severity With Respiratory Failure. EBioMedicine (2021) 66:103339. doi: 10.1016/ j.ebiom.2021.103339

176. Giovannoni F, Li Z, Garcia CC, Quintana FJ. A Potential Role for AHR in SARS-CoV-2 Pathology. Res Square (2020) 1-12. doi: 10.21203/rs.3.rs25639/v1

177. Giovannoni F, Bosch I, Polonio CM, Torti MF, Wheeler MA, Li Z, et al. AHR Is a Zika Virus Host Factor and a Candidate Target for Antiviral Therapy. Nat Neurosci (2020) 23:939-51. doi: 10.1038/s41593-020-0664-0

178. Giovannoni F, Quintana FJ. SARS-CoV-2-Induced Lung Pathology: AHR as a Candidate Therapeutic Target. Cell Res (2021) 31:1-2. doi: 10.1038/s41422020-00447-9

179. Zhao H, Chen L, Yang T, Feng Y, Vaziri ND, Liu B, et al. Aryl Hydrocarbon Receptor Activation Mediates Kidney Disease and Renal Cell Carcinoma. J Trans Med (2019) 17:1-14. doi: 10.1186/s12967-019-2054-5

180. DiNatale BC, Murray IA, Schroeder JC, Flaveny CA, Lahoti TS, Laurenzana EM, et al. Kynurenic Acid Is a Potent Endogenous Aryl Hydrocarbon Receptor Ligand That Synergistically Induces Interleukin-6 in the Presence of Inflammatory Signaling. Toxicol Sci (2010) 115:89-97. doi: 10.1093/toxsci/ $\mathrm{kfq} 024$

181. Andrade AF, Borges KS, Castro-Gamero AM, Silveira VS, Suazo VK, Oliveira JC, et al. Zebularine Induces Chemosensitization to Methotrexate and Efficiently Decreases AhR Gene Methylation in Childhood Acute Lymphoblastic Leukemia Cells. Anticancer Drugs (2014) 25:72-81. doi: 10.1097/CAD.0000000000000028
182. Singh NP, Singh UP, Singh B, Price RL, Nagarkatti M, Nagarkatti PS. Activation of Aryl Hydrocarbon Receptor (AhR) Leads to Reciprocal Epigenetic Regulation of FoxP3 and IL-17 Expression and Amelioration of Experimental Colitis. PloS One (2011) 6:e23522. doi: 10.1371/journal.pone.0023522

183. Lv J, Yu P, Wang Z, Deng W, Bao L, Liu J, et al. ACE2 Expression is Regulated by AhR in SARS-CoV-2-Infected Macaques. Cell Mol Immunol (2021) 18:1308-10. doi: 10.1038/s41423-021-00672-1

184. Zhong W, Li B, Xu Y, Yang P, Chen R, Wang Z, et al. Hypermethylation of the Micro-RNA 145 Promoter Is the Key Regulator for NLRP3 Inflammasome-Induced Activation and Plaque Formation. JACC: Basic to Trans Sci (2018) 3:604-24. doi: 10.1016/j.jacbts.2018.06.004

185. Huai W, Zhao R, Song H, Zhao J, Zhang L, Zhang L, et al. Aryl Hydrocarbon Receptor Negatively Regulates NLRP3 Inflammasome Activity by Inhibiting NLRP3 Transcription. Nat Commun (2014) 5:1-9. doi: 10.1038/ ncomms5738

186. Sagulenko V, Thygesen SJ, Sester DP, Idris A, Cridland JA, Vajjhala PR, et al. AIM2 and NLRP3 Inflammasomes Activate Both Apoptotic and Pyroptotic Death Pathways via ASC. Cell Death Differ (2013) 20:1149-60. doi: 10.1038/ cdd.2013.37

187. Yang Y, Wang H, Kouadir M, Song H, Shi F. Recent Advances in the Mechanisms of NLRP3 Inflammasome Activation and Its Inhibitors. Cell Death Dis (2019) 10:1-11. doi: 10.1038/s41419-019-1413-8

188. Xia S, Zhang Z, Magupalli VG, Pablo JL, Dong Y, Vora SM, et al. Gasdermin D Pore Structure Reveals Preferential Release of Mature Interleukin-1. Nature (2021) 593:607-11. doi: 10.1038/s41586-021-03478-3

189. Baazm M, Ghafarizadeh AA, Noshad Kamran AR, Beyer C, Zendedel A. Presence of The NLRP3 Inflammasome Components in Semen of Varicocele Patients. Int J Fertil Steril (2020) 14:46-50. doi: 10.22074/ijfs.2020.5734[doi

190. Su Y, Zhang Y, Hu Z, He L, Wang W, Xu J, et al. Prokineticin 2 via CalciumSensing Receptor Activated NLRP3 Inflammasome Pathway in the Testicular Macrophages of Uropathogenic Escherichia Coli-Induced Orchitis. Front Immunol (2020) 11:570872. doi: 10.3389/fimmu.2020.570872

191. Carrell DT. Epigenetics of the Male Gamete. Fertil Steril (2012) 97:267-74. doi: 10.1016/j.fertnstert.2011.12.036

192. Oliva R. Protamines and Male Infertility. Hum Reprod Update (2006) 12:417-35. doi: 10.1093/humupd/dml009

193. Li H, Xiao X, Zhang J, Zafar MI, Wu C, Long Y, et al. Impaired Spermatogenesis in COVID-19 Patients. EClinicalMedicine (2020) 28:100604. doi: 10.1016/j.eclinm.2020.100604

194. Mieusset R, Bujan L. Testicular Heating and Its Possible Contributions to Male Infertility: A Review. Int J Androl (1995) 18:169-84. doi: 10.1111/ j.1365-2605.1995.tb00408.x

195. Kohli RM, Zhang Y. TET Enzymes, TDG and the Dynamics of DNA Demethylation. Nature (2013) 502:472-9. doi: 10.1038/nature12750

196. Kriaucionis S, Heintz N. The Nuclear DNA Base 5-Hydroxymethylcytosine Is Present in Purkinje Neurons and the Brain. Science (2009) 324:929-30. doi: 10.1126/science.1169786[doi

197. Ito S, Shen L, Dai Q, Wu SC, Collins LB, Swenberg JA, et al. Tet Proteins can Convert 5-Methylcytosine to 5-Formylcytosine and 5-Carboxylcytosine. Science (2011) 333:1300-3. doi: 10.1126/science.1210597[doi

198. He YF, Li BZ, Li Z, Liu P, Wang Y, Tang Q, et al. Tet-Mediated Formation of 5-Carboxylcytosine and Its Excision by TDG in Mammalian DNA. Science (2011) 333:1303-7. doi: 10.1126/science.1210944[doi

199. Hahn MA, Qiu R, Wu X, Li AX, Zhang H, Wang J, et al. Dynamics of 5Hydroxymethylcytosine and Chromatin Marks in Mammalian Neurogenesis. Cell Rep (2013) 3:291-300. doi: 10.1016/j.celrep.2013.01.011

200. Rodríguez-Aguilera JR, Ecsedi S, Goldsmith C, Cros M, Domínguez-López $\mathrm{M}$, Guerrero-Celis N, et al. Genome-Wide 5-Hydroxymethylcytosine $(5 \mathrm{hmc})$ Emerges at Early Stage of In Vitro Differentiation of a Putative Hepatocyte Progenitor. Sci Rep (2020) 10:1-16. doi: 10.1038/s41598-02064700-2

201. Yue X, Trifari S, Äijö T, Tsagaratou A, Pastor WA, Zepeda-Martínez JA, et al. Control of Foxp3 Stability Through Modulation of TET Activity. J Exp Med (2016) 213:377-97. doi: 10.1084/jem.20151438

202. Carty SA, Gohil M, Banks LB, Cotton RM, Johnson ME, Stelekati E, et al. The Loss of TET2 Promotes CD8(+) T Cell Memory Differentiation. J Immunol (2018) 200:82-91. doi: 10.4049/jimmunol.1700559[doi 
203. An J, González-Avalos E, Chawla A, Jeong M, López-Moyado IF, Li W, et al. Acute Loss of TET Function Results in Aggressive Myeloid Cancer in Mice. Nat Commun (2015) 6:1-14. doi: 10.1038/ncomms10071

204. Orlanski S, Labi V, Reizel Y, Spiro A, Lichtenstein M, Levin-Klein R, et al. Tissue-Specific DNA Demethylation Is Required for Proper B-Cell Differentiation and Function. Proc Natl Acad Sci USA (2016) 113:5018-23. doi: 10.1073/pnas.1604365113[doi

205. Yue X, Trifari S, Äijö T, Tsagaratou A, Pastor WA, Zepeda-Martínez JA, et al. Control of Foxp3 Stability Through Modulation of TET Activity. J Exp Med (2016) 213:377-97. doi: 10.1084/jem.20151438

206. Yang R, Qu C, Zhou Y, Konkel JE, Shi S, Liu Y, et al. Hydrogen Sulfide Promotes Tet1-And Tet2-Mediated Foxp3 Demethylation to Drive Regulatory $\mathrm{T}$ Cell Differentiation and Maintain Immune Homeostasis. Immunity (2015) 43:251-63. doi: 10.1016/j.immuni.2015.07.017

207. Zhao Z, Lan M, Li J, Dong Q, Li X, Liu B, et al. The Proinflammatory Cytokine Tnfo Induces DNA Demethylation-Dependent and-Independent Activation of Interleukin-32 Expression. J Biol Chem (2019) 294:6785-95. doi: $10.1074 /$ jbc.RA118.006255

208. Liu X, Wang X, Liu N, Zhu K, Zhang S, Duan X, et al. TET2 Is Involved in DNA Hydroxymethylation, Cell Proliferation and Inflammatory Response in Keratinocytes. Mol Med Rep (2020) 21:1941-9. doi: 10.3892/mmr.2020.10989

209. Stanczak MA, Sanin DE, Apostolova P, Nerz G, Lampaki D, Hofmann M, et al. IL-33 Expression in Response to SARS-CoV-2 Correlates With Seropositivity in COVID-19 Convalescent Individuals. Nat Commun (2021) 12:1-9. doi: 10.1038/s41467-021-22449-w

210. Mohebbi SR, Baghaei K, Rostami-Nejad M, Mojarad EN, Mirjalali H, Yadegar A, et al. Significant Changes of CD4, FOXP3, CD25, and IL6 Expression Level in Iranian COVID-19 Patients. Gastroenterol Hepatol Bed Bench (2020) 13:388.

211. Haseeb A, Haqqi T. IL- $1 \beta$ and TNF- $\alpha$ Regulate the Global Hydroxymethylation of Genomic DNA by Modulating the Expression and Activity of TET-1 in Human OA Chondrocytes. Osteoarthritis Cartilage (2013) 21:S15. doi: 10.1016/j.joca.2013.02.053

212. Kang CK, Han G, Kim M, Kim G, Shin HM, Song K, et al. Aberrant Hyperactivation of Cytotoxic T-Cell as a Potential Determinant of COVID19 Severity. Int J Infect Dis (2020) 97:313-21. doi: 10.1016/j.ijid.2020.05.106

213. van der Made CI, Simons A, Schuurs-Hoeijmakers J, Van Den Heuvel G, Mantere $\mathrm{T}$, Kersten S, et al. Presence of Genetic Variants Among Young Men With Severe COVID-19. JAMA (2020) 324:663-73. doi: 10.1001/jama.2020.13719

214. Acharya D, Liu G, Gack MU. Dysregulation of Type I Interferon Responses in COVID-19. Nat Rev Immunol (2020) 20:397-8. doi: 10.1038/s41577-0200346-X

215. Hadjadj J, Yatim N, Barnabei L, Corneau A, Boussier J, Smith N, et al. Impaired Type I Interferon Activity and Inflammatory Responses in Severe COVID-19 Patients. Science (2020) 369:718-24. doi: 10.1126/science.abc6027[doi

216. Schröder O, Schulte K, Ostermann P, Röher H, Ekkernkamp A, Laun RA. Heat Shock Protein 70 Genotypes HSPA1B and HSPA1L Influence Cytokine Concentrations and Interfere With Outcome After Major Injury. Crit Care Med (2003) 31:73-9. doi: 10.1097/00003246-200301000-00011

217. Muhammad JS, Saheb Sharif-Askari N, Cui Z, Hamad M, Halwani R. SARSCoV-2 Infection-Induced Promoter Hypomethylation as an Epigenetic Modulator of Heat Shock Protein A1L (HSPA1L) Gene. Front Genet (2021) 12:129. doi: 10.3389/fgene.2021.622271

218. Pruimboom L. Methylation Pathways and SARS-CoV-2 Lung Infiltration and Cell Membrane-Virus Fusion Are Both Subject to Epigenetics. Front Cell Infect Microbiol (2020) 10:290. doi: 10.3389/fcimb.2020.00290

219. Wang GZ, Wang Y, Goff SP. Histones Are Rapidly Loaded Onto Unintegrated Retroviral DNAs Soon After Nuclear Entry. Cell Host Microbe (2016) 20:798-809. doi: 10.1016/j.chom.2016.10.009

220. Parekh BS, Maniatis T. Virus Infection Leads to Localized Hyperacetylation of Histones H3 and H4 at the IFN- $\beta$ Promoter. Mol Cell (1999) 3:125-9. doi: 10.1016/S1097-2765(00)80181-1

221. Zhao S, Zhang X, Li H. Beyond Histone Acetylation-Writing and Erasing Histone Acylations. Curr Opin Struct Biol (2018) 53:169-77. doi: 10.1016/ j.sbi.2018.10.001

222. Arrowsmith CH, Bountra C, Fish PV, Lee K, Schapira M. Epigenetic Protein Families: A New Frontier for Drug Discovery. Nat Rev Drug Discov (2012) 11:384-400. doi: $10.1038 / \mathrm{nrd} 3674$
223. Jones PA, Issa JJ, Baylin S. Targeting the Cancer Epigenome for Therapy. Nat Rev Genet (2016) 17:630. doi: 10.1038/nrg.2016.93

224. Knackstedt SL, Georgiadou A, Apel F, Abu-Abed U, Moxon CA, Cunnington AJ, et al. Neutrophil Extracellular Traps Drive Inflammatory Pathogenesis in Malaria. Sci Immunol (2019) 4:1-13. doi: 10.1126/sciimmunol.aaw0336

225. Brinkmann V, Zychlinsky A. Neutrophil Extracellular Traps: Is Immunity the Second Function of Chromatin? J Cell Biol (2012) 198:773-83. doi: $10.1083 /$ jcb.201203170

226. Zindel J, Kubes P. DAMPs, PAMPs, and LAMPs in Immunity and Sterile Inflammation. Annu Rev Pathol: Mech Dis (2020) 15:493-518. doi: 10.1146/ annurev-pathmechdis-012419-032847

227. Conti P, Caraffa A, Gallenga C, Ross R, Kritas S, Frydas I, et al. Coronavirus19 (SARS-CoV-2) Induces Acute Severe Lung Inflammation via IL-1 Causing Cytokine Storm in COVID-19: A Promising Inhibitory Strategy. J Biol Regul Homeost Agents (2020) 34:1971-5.

228. Cuevas AM, Clark JM, Potter JJ. Increased TLR/MyD88 Signaling in Patients With Obesity: Is There a Link to COVID-19 Disease Severity? Int J Obes (2021) 45:1152-4. doi: 10.1038/s41366-021-00768-8

229. Du Clos TW, Zlock LT, Rubin RL. Analysis of the Binding of C-Reactive Protein to Histones and Chromatin. J Immunol (1988) 141:4266-70.

230. Bosmann M, Grailer JJ, Ruemmler R, Russkamp NF, Zetoune FS, Sarma JV, et al. Extracellular Histones Are Essential Effectors of C5aR-And C5L2Mediated Tissue Damage and Inflammation in Acute Lung Injury. FASEB J (2013) 27:5010-21. doi: 10.1096/fj.13-236380

231. Fattahi F, Frydrych LM, Bian G, Kalbitz M, Herron TJ, Malan EA, et al. Role of Complement C5a and Histones in Septic Cardiomyopathy. Mol Immunol (2018) 102:32-41. doi: 10.1016/j.molimm.2018.06.006

232. Li M, Dong Y, Wang H, Guo W, Zhou H, Zhang Z, et al. Cardiovascular Disease Potentially Contributes to the Progression and Poor Prognosis of COVID-19. Nutr Metab Cardiovasc Dis (2020) 30:1061-7. doi: 10.1016/ j.numecd.2020.04.013

233. Hsieh I, White M, Hoeksema M, Deluna X, Hartshorn K. Histone H4 Potentiates Neutrophil Inflammatory Responses to Influenza A Virus: Down-Modulation by H4 Binding to C-Reactive Protein and Surfactant Protein D. PloS One (2021) 16:e247605. doi: 10.1371/journal.pone.0247605

234. Hatakeyama D, Shoji M, Yamayoshi S, Yoh R, Ohmi N, Takenaka S, et al. Influenza A Virus Nucleoprotein Is Acetylated by Histone Acetyltransferases PCAF and GCN5. J Biol Chem (2018) 293:7126-38. doi: 10.1074/ jbc.RA117.001683

235. Terreni M, Valentini P, Liverani V, Gutierrez MI, Di Primio C, Di Fenza A, et al. GCN5-Dependent Acetylation of HIV-1 Integrase Enhances Viral Integration. Retrovirology (2010) 7:1-16. doi: 10.1186/1742-4690-7-18

236. Steffen U, Koeleman CA, Sokolova MV, Bang H, Kleyer A, Rech J, et al. IgA Subclasses Have Different Effector Functions Associated With Distinct Glycosylation Profiles. Nat Commun (2020) 11:1-12. doi: 10.1038/s41467019-13992-8

237. Rice JC, Allis CD. Histone Methylation Versus Histone Acetylation: New Insights Into Epigenetic Regulation. Curr Opin Cell Biol (2001) 13:263-73. doi: 10.1016/S0955-0674(00)00208-8

238. Castillo-Aguilera O, Depreux P, Halby L, Arimondo PB, Goossens L. DNA Methylation Targeting: The DNMT/HMT Crosstalk Challenge. Biomolecules (2017) 7:3. doi: 10.3390/biom7010003

239. Lee J, Wang C, Xu S, Cho Y, Wang L, Feng X, et al. H3K4 Mono-and DiMethyltransferase MLL4 Is Required for Enhancer Activation During Cell Differentiation. elife (2013) 2:e01503. doi: 10.7554/eLife.01503

240. Ortmann BM, Burrows N, Lobb IT, Arnaiz E, Wit N, Bailey PS, et al. The HIF Complex Recruits the Histone Methyltransferase SET1B to Activate Specific Hypoxia-Inducible Genes. Nat Genet (2021) 53:1022-35. doi: 10.1038/s41588-021-00887-y

241. Lawlor L, Yang XB. Harnessing the HDAC-histone Deacetylase Enzymes, Inhibitors and How These can be Utilised in Tissue Engineering. Int J Oral Sci (2019) 11:1-11. doi: 10.1038/s41368-019-0053-2

242. Yang X, Seto E. HATs and HDACs: From Structure, Function and Regulation to Novel Strategies for Therapy and Prevention. Oncogene (2007) 26:5310-0. doi: 10.1038/sj.onc.1210599

243. Irwin NA, Martin BJ, Young BP, Browne MJ, Flaus A, Loewen CJ, et al. Viral Proteins as a Potential Driver of Histone Depletion in Dinoflagellates. Nat Commun (2018) 9:1-8. doi: 10.1038/s41467-018-03993-4 
244. Arzumanyan A, Friedman T, Kotei E, Ng IO, Lian Z, Feitelson MA. Epigenetic Repression of E-Cadherin Expression by Hepatitis B Virus X Antigen in Liver Cancer. Oncogene (2012) 31:563-72. doi: 10.1038/onc.2011.255

245. Finzer P, Kuntzen C, Soto U, Zur Hausen H, Rösl F. Inhibitors of Histone Deacetylase Arrest Cell Cycle and Induce Apoptosis in Cervical Carcinoma Cells Circumventing Human Papillomavirus Oncogene Expression. Oncogene (2001) 20:4768-76. doi: 10.1038/sj.onc.1204652

246. Banerjee NS, Moore DW, Broker TR, Chow LT. Vorinostat, a Pan-HDAC Inhibitor, Abrogates Productive HPV-18 DNA Amplification. Proc Natl Acad Sci USA (2018) 115:E11138-47. doi: 10.1073/pnas.1801156115[doi

247. Choi KC, Jung MG, Lee YH, Yoon JC, Kwon SH, Kang HB, et al. Epigallocatechin-3-Gallate, a Histone Acetyltransferase Inhibitor, Inhibits EBV-Induced B Lymphocyte Transformation via Suppression of RelA Acetylation. Cancer Res (2009) 69:583-92. doi: 10.1158/0008-5472.CAN08-2442[doi

248. Jafarzadeh A, Nemati M, Jafarzadeh S. Contribution of STAT3 to the Pathogenesis of COVID-19. Microb Pathog (2021) 154:104836. doi: 10.1016/j.micpath.2021.104836

249. Hirano T, Murakami M. COVID-19: A New Virus, But a Familiar Receptor and Cytokine Release Syndrome. Immunity (2020) 52:731-3. doi: 10.1016/ j.immuni.2020.04.003

250. Zhu L, Fung S, Xie G, Wong LR, Jin D, Cai Z. Identification of Lysine Acetylation Sites on MERS-CoV Replicase Pplab. Mol Cell Proteomics (2020) 19:1303-9. doi: 10.1074/mcp.RA119.001897

251. Ma-Lauer Y, Carbajo-Lozoya J, Hein MY, Muller MA, Deng W, Lei J, et al. P53 Down-Regulates SARS Coronavirus Replication and Is Targeted by the SARS-Unique Domain and PLpro via E3 Ubiquitin Ligase RCHY1. Proc Natl Acad Sci USA (2016) 113:E5192-201. doi: 10.1073/pnas.1603435113[doi

252. Takahashi Y, Hayakawa A, Sano R, Fukuda H, Harada M, Kubo R, et al. Histone Deacetylase Inhibitors Suppress ACE2 and ABO Simultaneously, Suggesting a Preventive Potential Against COVID-19. Sci Rep (2021) 11:1-9. doi: 10.1038/s41598-021-82970-2

253. Almadhi MA, Abdulrahman A, Alawadhi A, Rabaan AA, Atkin S, AlQahtani M. The Effect of ABO Blood Group and Antibody Class on the Risk of COVID-19 Infection and Severity of Clinical Outcomes. Sci Rep (2021) 11:15. doi: 10.1038/s41598-021-84810-9

254. Zhao J, Yang Y, Huang H, Li D, Gu D, Lu X, et al. Relationship Between the ABO Blood Group and the COVID-19 Susceptibility. Clin Infect Dis (2020) 78:328-31. doi: 110.1093/cid/ciaa1150

255. Kim MS, Kwon HJ, Lee YM, Baek JH, Jang J, Lee S, et al. Histone Deacetylases Induce Angiogenesis by Negative Regulation of Tumor Suppressor Genes. Nat Med (2001) 7:437-43. doi: 10.1038/86507

256. Serebrovska ZO, Chong EY, Serebrovska TV, Tumanovska LV, Xi L. Hypoxia, HIF-1 $\alpha$, and COVID-19: From Pathogenic Factors to Potential Therapeutic Targets. Acta Pharmacol Sin (2020) 41:1539-46. doi: 10.1038/ s41401-020-00554-8

257. Ackermann M, Verleden SE, Kuehnel M, Haverich A, Welte T, Laenger F, et al. Pulmonary Vascular Endothelialitis, Thrombosis, and Angiogenesis in Covid-19. N Engl J Med (2020) 383:120-8. doi: 10.1056/NEJMoa2015432

258. Kong Y, Han J, Wu X, Zeng H, Liu J, Zhang H. VEGF-D: A Novel Biomarker for Detection of COVID-19 Progression. Crit Care (2020) 24:1-4. doi: $10.1186 /$ s13054-020-03079-y

259. Litke C, Bading H, Mauceri D. Histone Deacetylase 4 Shapes Neuronal Morphology via a Mechanism Involving Regulation of Expression of Vascular Endothelial Growth Factor D. J Biol Chem (2018) 293:8196-207. doi: $10.1074 /$ jbc.RA117.001613

260. Lai T, Tian B, Cao C, Hu Y, Zhou J, Wang Y, et al. HDAC2 Suppresses IL17A-Mediated Airway Remodeling in Human and Experimental Modeling of COPD. Chest (2018) 153:863-75. doi: 10.1016/j.chest.2017.10.031

261. Royce SG, Karagiannis TC. Histone Deacetylases and Their Inhibitors: New Implications for Asthma and Chronic Respiratory Conditions. Curr Opin Allergy Clin Immunol (2014) 14:44-8. doi: 10.1097/ACI.0000000 000000029

262. Barnes PJ. Corticosteroid Resistance in Patients With Asthma and Chronic Obstructive Pulmonary Disease. J Allergy Clin Immunol (2013) 131:636-45. doi: 10.1016/j.jaci.2012.12.1564

263. Ahmad R, Al-Mass A, Atizado V, Al-Hubail A, Al-Ghimlas F, Al-Arouj M, et al. Elevated Expression of the Toll Like Receptors 2 and 4 in Obese
Individuals: Its Significance for Obesity-Induced Inflammation. J Inflammation (2012) 9:1-11. doi: 10.1186/1476-9255-9-48

264. Hinohara K, Wu H, Vigneau S, McDonald TO, Igarashi KJ, Yamamoto KN, et al. KDM5 Histone Demethylase Activity Links Cellular Transcriptomic Heterogeneity to Therapeutic Resistance. Cancer Cell (2018) 34:939-953. e9. doi: 10.1016/j.ccell.2018.10.014

265. Wu L, Cao J, Cai WL, Lang SM, Horton JR, Jansen DJ, et al. KDM5 Histone Demethylases Repress Immune Response via Suppression of STING. PloS Biol (2018) 16:e2006134. doi: 10.1371/journal.pbio.2006134

266. Chen X, Yang X, Zheng Y, Yang Y, Xing Y, Chen Z. SARS Coronavirus Papain-Like Protease Inhibits the Type I Interferon Signaling Pathway Through Interaction With the STING-TRAF3-TBK1 Complex. Protein Cell (2014) 5:369-81. doi: 10.1007/s13238-014-0026-3

267. Rui Y, Su J, Shen S, Hu Y, Huang D, Zheng W, et al. Unique and Complementary Suppression of cGAS-STING and RNA Sensing-Triggered Innate Immune Responses by SARS-CoV-2 Proteins. Signal Transduction Targeted Ther (2021) 6:1-11. doi: 10.1038/s41392-021-00515-5

268. Hu H, Qiao J, Liu F, Wang J, Sha S, He Q, et al. The STING-IRF3 Pathway Is Involved in Lipotoxic Injury of Pancreatic $\beta$ Cells in Type 2 Diabetes. Mol Cell Endocrinol (2020) 518:110890. doi: 10.1016/j.mce. 2020.110890

269. Berthelot J, Liote F. COVID-19 as a STING Disorder With Delayed OverSecretion of Interferon-Beta. EBioMedicine (2020) 56:102801. doi: 10.1016/ j.ebiom.2020.102801

270. Bai J, Liu F. The cGAS-cGAMP-STING Pathway: A Molecular Link Between Immunity and Metabolism. Diabetes (2019) 68:1099-108. doi: 10.2337/ dbi18-0052[doi

271. Qiao J, Cui C, Qing L, Wang L, He T, Yan F, et al. Activation of the STINGIRF3 Pathway Promotes Hepatocyte Inflammation, Apoptosis and Induces Metabolic Disorders in Nonalcoholic Fatty Liver Disease. Metab Clin Exp (2018) 81:13-24. doi: 10.1016/j.metabol.2017.09.010

272. Su C, Wang L, Yoo D. Activation of NF- Kb and Induction of Proinflammatory Cytokine Expressions Mediated by ORF7a Protein of SARS-CoV-2. Sci Rep (2021) 11:1-12. doi: 10.1038/s41598-021-92941-2

273. Lv J, Yu P, Wang Z, Deng W, Bao L, Liu J, et al. ACE2 Expression Is Regulated by AhR in SARS-CoV-2-Infected Macaques. Cell Mol Immunol (2021) 18:1308-10. doi: 10.1038/s41423-021-00672-1

274. Giovannoni F, Quintana FJ. SARS-CoV-2-Induced Lung Pathology: AHR as a Candidate Therapeutic Target. Cell Res (2021) 31:1-2. doi: 10.1038/s41422020-00447-9

275. Wang G, Zhang L, Zhao X, Gao S, Qu L, Yu H, et al. The Aryl Hydrocarbon Receptor Mediates Tobacco-Induced PD-L1 Expression and Is Associated With Response to Immunotherapy. Nat Commun (2019) 10:1-13. doi: 10.1038/s41467-019-08887-7

276. Esser C, Rannug A. The Aryl Hydrocarbon Receptor in Barrier Organ Physiology, Immunology, and Toxicology. Pharmacol Rev (2015) 67:25979. doi: 10.1124/pr.114.009001[doi

277. Zhao R, He Q, Sha S, Song J, Qin J, Liu P, et al. Increased AHR Transcripts Correlate With Pro-Inflammatory T-Helper Lymphocytes Polarization in Both Metabolically Healthy Obesity and Type 2 Diabetic Patients. Front Immunol (2020) 11:1644. doi: 10.3389/fimmu.2020.01644

278. Ziegler CG, Allon SJ, Nyquist SK, Mbano IM, Miao VN, Tzouanas CN, et al. SARS-CoV-2 Receptor ACE2 is an Interferon-Stimulated Gene in Human Airway Epithelial Cells and Is Detected in Specific Cell Subsets Across Tissues. Cell (2020) 181:1016-35.e19. doi: 10.1016/j.cell.2020.04.035

279. Xu Y, Liu L. Curcumin Alleviates Macrophage Activation and Lung Inflammation Induced by Influenza Virus Infection Through Inhibiting the NF-kb Signaling Pathway. Influenza other Respir viruses (2017) 11:45763. doi: 10.1111 /irv.12459

280. Lammers T, Sofias AM, van der Meel R, Schiffelers R, Storm G, Tacke F, et al. Dexamethasone Nanomedicines for COVID-19. Nat nanotechnol (2020) 15:622-4. doi: 10.1038/s41565-020-0752-z

281. Nishiumi S, Yoshida K, Ashida H. Curcumin Suppresses the Transformation of an Aryl Hydrocarbon Receptor Through Its Phosphorylation. Arch Biochem Biophys (2007) 466:267-73. doi: 10.1016/j.abb.2007.08.007

282. Hassan F, Rehman MS, Khan MS, Ali MA, Javed A, Nawaz A, et al. Curcumin as an Alternative Epigenetic Modulator: Mechanism of Action and Potential Effects. Front Genet (2019) 10:514. doi: 10.3389/fgene.2019.00514 
283. Stejskalova L, Rulcova A, Vrzal R, Dvorak Z, Pavek P. Dexamethasone Accelerates Degradation of Aryl Hydrocarbon Receptor (AHR) and Suppresses CYP1A1 Induction in Placental JEG-3 Cell Line. Toxicol Lett (2013) 223:183-91. doi: 10.1016/j.toxlet.2013.09.014

284. Vrzal R, Stejskalova L, Monostory K, Maurel P, Bachleda P, Pavek P, et al. Dexamethasone Controls Aryl Hydrocarbon Receptor (AhR)-Mediated CYP1A1 and CYP1A2 Expression and Activity in Primary Cultures of Human Hepatocytes. Chem Biol Interact (2009) 179:288-96. doi: 10.1016/ j.cbi.2008.10.035

285. Puyskens A, Stinn A, van der Vaart M, Kreuchwig A, Protze J, Pei G, et al. Aryl Hydrocarbon Receptor Modulation by Tuberculosis Drugs Impairs Host Defense and Treatment Outcomes. Cell Host Microbe (2020) 27:23848. doi: 10.1016/j.chom.2019.12.005

286. Leclair HM, Tardif N, Paris A, Galibert M, Corre S. Role of Flavonoids in the Prevention of AhR-Dependent Resistance During Treatment With BRAF Inhibitors. Int J Mol Sci (2020) 21:5025. doi: 10.3390/ijms21145025

287. Corre S, Tardif N, Mouchet N, Leclair HM, Boussemart L, Gautron A, et al. Sustained Activation of the Aryl Hydrocarbon Receptor Transcription Factor Promotes Resistance to BRAF-Inhibitors in Melanoma. Nat Commun (2018) 9:4775-018-06951-2. doi: 10.1038/s41467-018-06951-2[doi

288. Mohammadi-Bardbori A, Bengtsson J, Rannug U, Rannug A, Wincent E. Quercetin, Resveratrol, and Curcumin Are Indirect Activators of the Aryl Hydrocarbon Receptor (AHR). Chem Res Toxicol (2012) 25:1878-84. doi: 10.1021/tx300169e

289. Dai X, Yin H, Sun L, Hu X, Zhou C, Zhou Y, et al. Potential Therapeutic Efficacy of Curcumin in Liver Cancer. Asian Pac J Cancer Prev (2013) 14:3855-9. doi: 10.7314/APJCP.2013.14.6.3855

290. Marquardt JU, Gomez-Quiroz L, Camacho LOA, Pinna F, Lee Y, Kitade M, et al. Curcumin Effectively Inhibits Oncogenic NF- $\mathrm{b}$ Signaling and
Restrains Stemness Features in Liver Cancer. J Hepatol (2015) 63:661-9. doi: 10.1016/j.jhep.2015.04.018

291. Stejskalova L, Rulcova A, Vrzal R, Dvorak Z, Pavek P. Dexamethasone Accelerates Degradation of Aryl Hydrocarbon Receptor (AHR) and Suppresses CYP1A1 Induction in Placental JEG-3 Cell Line. Toxicol Lett (2013) 223:183-91. doi: 10.1016/j.toxlet.2013.09.014

292. Gabbia D, Pozzo L, Zigiotto G, Roverso M, Sacchi D, Dalla Pozza A, et al. Dexamethasone Counteracts Hepatic Inflammation and Oxidative Stress in Cholestatic Rats via CAR Activation. PloS One (2018) 13:e0204336. doi: 10.1371/journal.pone.0204336

Conflict of Interest: The authors declare that the research was conducted in the absence of any commercial or financial relationships that could be construed as a potential conflict of interest.

Publisher's Note: All claims expressed in this article are solely those of the authors and do not necessarily represent those of their affiliated organizations, or those of the publisher, the editors and the reviewers. Any product that may be evaluated in this article, or claim that may be made by its manufacturer, is not guaranteed or endorsed by the publisher.

Copyright (C) 2021 Kgatle, Lawal, Mashabela, Boshomane, Koatale, Mahasha, Ndlovu, Vorster, Rodrigues, Zeevaart, Gordon, Moura-Alves and Sathekge. This is an openaccess article distributed under the terms of the Creative Commons Attribution License (CC BY). The use, distribution or reproduction in other forums is permitted, provided the original author(s) and the copyright owner(s) are credited and that the original publication in this journal is cited, in accordance with accepted academic practice. No use, distribution or reproduction is permitted which does not comply with these terms. 